(C) The Author(s) 2021. Published by Oxford University Press on behalf of The Review of Economic Studies Limited.

This is an Open Access article distributed under the terms of the Creative Commons Attribution License

(http://creativecommons.org/licenses/by/4.0/), which permits unrestricted reuse, distribution, and reproduction in any medium, provided the original work is properly cited. For commercial re-use, please

contactjournals.permissions@oup.com

Advance access publication 01 March 2021

\title{
Credit Shocks and Equilibrium Dynamics in Consumer Durable Goods Markets
}

\author{
ALESSANDRO GAVAZZA \\ Department of Economics, London School of Economics \\ and \\ ANDREA LANTERI \\ Department of Economics, Duke University
}

First version received December 2018; Editorial decision December 2020; Accepted February 2021 (Eds.)

\begin{abstract}
This article studies equilibrium dynamics in consumer durable goods markets after aggregate credit shocks. We introduce two novel features into a general-equilibrium model of durable consumption with heterogeneous households facing idiosyncratic income risk and borrowing constraints: (1) indivisible durable goods are vertically differentiated in their quality and (2) trade on secondary markets at marketclearing prices, with households endogenously choosing when to trade or scrap their durables. The model highlights a new transmission mechanism for macroeconomic shocks and successfully matches several empirical patterns that we document using data on U.S. car markets around the Great Recession. After a tightening of the borrowing limit, debt-constrained households postpone the decision to scrap and upgrade their low-quality cars, which depresses mid-quality car prices. In turn, this effect reduces wealthy households' incentives to replace their mid-quality cars with high-quality ones, thereby decreasing new-car sales. We further use our framework to evaluate targeted fiscal stimulus policies such as the Car Allowance Rebate System in 2009 ("Cash for Clunkers").
\end{abstract}

Key words: Credit constraints, Durable goods

JEL Codes: E21, E32, L62

\section{INTRODUCTION}

Expenditures on consumer durable goods are a large, highly volatile, and procyclical component of Gross Domestic Product (GDP). Car markets around the Great Recession are a stark example of this volatility: Figure 1 shows that new-car registrations in the U.S. dropped from approximately 20 million in 2007 to 12 million in 2009 and recovered to 20 million by 2013 . This sharp decline accounted for over half of the total reduction in consumer expenditures on durable goods, implying

The editor in charge of this paper was Veronica Guerrieri. 


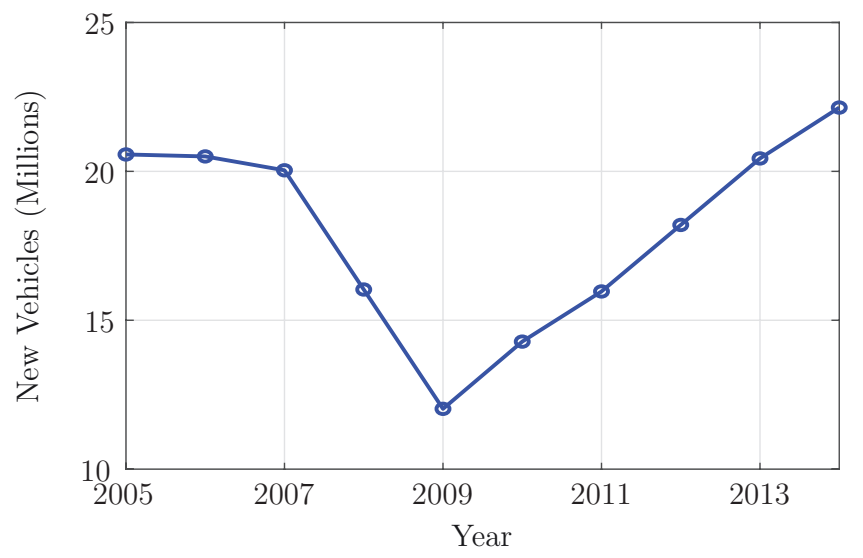

FIGURE 1

New-vehicle registrations from 2005 to 2014, in millions.

that understanding this component of consumer spending is critical in accounting for household dynamics in the Great Recession. ${ }^{1}$

The objective of this article is to study the equilibrium dynamics of consumer durable goods markets in response to macroeconomic shocks, with a special focus on car markets. A key contribution of our analysis is to uncover and quantify a new mechanism that transmits aggregate credit shocks to purchases of new durable goods through equilibrium price changes in secondary markets.

We begin our analysis by examining different data sources in order to gain a broad picture of household vehicle holdings and equilibrium dynamics in car markets. These data reveal several interesting patterns that complement the drop in new-car sales during the Great Recession displayed in Figure 1. Most notably, (1) vehicle scrappage declined from 2007 to 2009; (2) the cost of replacing a used car with a new one increased from 2007 to 2009, as used-car prices dropped and new-car prices remained stable; and (3) the fraction of households that replaced a used vehicle with a new one bottomed out during the Great Recession.

These facts motivate us to develop a macroeconomic model of durable consumption that features a notion of endogenous illiquidity, stemming from equilibrium dynamics in secondary markets. We use this novel framework to analyse the transmission mechanism of macroeconomic shocks to durable-goods purchases. The model includes the key elements needed to study this transmission: it allows for borrowing constraints that may affect households' vehicle holdings; it incorporates transaction costs that may trigger household inertia; and it is set in general equilibrium, because households' car purchases depend on both interest rates and car prices, which displayed large fluctuations in the Great Recession.

Our model is an incomplete-markets framework with uninsurable income shocks and durable adjustment. Durable goods feature two additional characteristics that are important in accounting for their equilibrium dynamics. First, the model features a quality ladder for durable goods: Cars differ in quality because of depreciation. Thus, because of indivisibility, cars of different qualities

1. Household expenditures on motor vehicles declined by approximately 100 billion U.S. dollars between 2007 and 2009. On average, this component accounts for approximately $35 \%$ of total consumer expenditures on durable goods. Moreover, the motor vehicle industry plays an important role in U.S. business cycles, because of its key position in the network structure of production (e.g. Atalay, 2017). Employment in this industry declined by approximately $35 \%$ during the Great Recession, leading to direct government interventions in the form of bailouts and stimulus to car purchases. 
are imperfect substitutes. ${ }^{2}$ Second, households choose when to replace their cars by trading them at market-clearing prices on secondary markets or scrapping them.

We parameterize the model to match several aggregate statistics for car markets and householdlevel cross-sectional moments on car ownership in the U.S., as well as empirical targets for household income and wealth. Our economy features a negative correlation between wealth and car age, consistent with evidence that Gavazza et al. (2014) report. Wealthier households tend to own new, high-quality cars; when the quality of these cars depreciates over time, wealthy households sell them and replace them with newer, higher-quality ones. Low-wealth households tend to own old, low-quality cars, scrapping them when their quality deteriorates further and replacing them with mid-quality, used cars. Thus, secondary markets play the fundamental role of reallocating used cars from higher-income households to lower-income ones.

In this setting, we consider a shock that permanently tightens credit limits, as in other recent papers that propose this shock as a plausible exogenous source of macroeconomic dynamics consistent with the experience of the Great Recession (e.g. Guerrieri and Lorenzoni, 2017; Huo and Ríos-Rull, 2016). As in these papers, a tighter borrowing constraint motivates all households to increase their savings, leading to a sharp decline in the equilibrium real interest rate. Importantly, in our model, low-wealth households-for whom the borrowing constraints become tighter-decide to postpone scrapping their old, low-quality vehicles. Because these low-wealth households are natural buyers of mid-quality, used cars, their decision to postpone scrappage leads to a decrease in the demand for these mid-quality cars, thereby lowering their price. Hence, high-wealth households, who normally trade in moderately used cars to replace them with new, high-quality ones, suffer an increase in the replacement cost of their vehicles and decide to delay their replacement. Thus, even though the change in the borrowing limit does not directly affect these wealthy households, the equilibrium dynamics in secondary markets prompt them to postpone their new-car purchases. In our calibration, this negative feedback effect of secondary markets on the primary market quantitatively dominates the positive effect of low interest rates on purchases of new durable goods. Hence, the model predicts a large decrease in new-car sales, as well as in scrappage and used prices, consistent with the empirical evidence we document.

The distinctive feature of our model is the endogenous illiquidity of durable goods, arising from the equilibrium dynamics in secondary markets. In our framework, the price of used durables falls in response to a credit tightening - that is, when the marginal value of liquidity is highest. This equilibrium effect renders durable goods a poor store of value and amplifies their cyclical dynamics. Critically, this mechanism is crucial in accounting for the large drop in new-car sales, as well as the positive comovement of scrappage and new sales observed in the data. We perform a rich series of decompositions and counterfactual analyses to show that this implication of our model is in stark contrast to the implications of models that do not account for secondary-market equilibrium.

We further enrich our model to study several interactions between durable goods markets and the macroeconomy, which allows us to quantify the importance of equilibrium dynamics in durable goods markets during the Great Recession. Specifically, we consider aggregate income

2. The large majority of households own a vehicle that is an imperfect substitute for a new vehicle, because of indivisibility. Specifically, our transaction data described in Section 3 show that the 10th percentile of the distribution of new-vehicle prices in 2007 equals \$16,239, whereas Table 1 of Jacobsen and van Benthem (2015) reports that the average price of a 3-year-old car in the U.S. equals approximately \$16,400 (in 2009 dollars). Moreover, the average lifetime of vehicles may exceed 15 years, depending on the model. All these facts together make it apparent that the large majority of households own a vehicle whose value is well below that of a cheap new car, and thus is an imperfect substitute for a new vehicle. 
shocks, endogenous changes in the marginal cost of new durable goods, and borrowing constraints that depend on the value of households' durable holdings - that is, collateral constraints. These features improve the quantitative performance of the model against the data. Most notably, a combination of credit tightening and an aggregate income decline accounts for almost the entire drop in new-car sales.

Finally, we use our model to evaluate the effects of targeted fiscal stimulus, in the form of car-replacement subsidies, similar to the "Cash for Clunkers" program implemented in the U.S. in 2009. We show that secondary markets play an important role in the transmission of these policy interventions. Specifically, we find that general-equilibrium effects dampen the stimulus of these subsidies on the demand for new cars, by depressing the trading and prices of used-car markets. Hence, these subsidies are less effective than models that do not consider general-equilibrium effects would predict.

The rest of the article is organized as follows. Section 2 highlights our contribution to the literature. Section 3 documents the key empirical patterns for vehicle prices and households' vehicle replacement during the Great Recession. Section 4 introduces our model, which we parameterize in Section 5. Section 6 considers the effects of macroeconomic shocks, such as an aggregate tightening of the borrowing limit and a negative aggregate income shock. Section 7 studies durable-replacement subsidies, and Section 8 concludes. The online appendices collect additional results.

\section{RELATED LITERATURE}

This article contributes to several strands of literature. First, since at least Mankiw (1982) and Bernanke (1985), understanding the dynamics of expenditures on durable goods has been an important question in macroeconomics. In their seminal paper, Grossman and Laroque (1990) develop a model of durables adjustment subject to transaction costs, proportional to the value of the current durable stock, motivating this assumption with the idea of indivisibility: In order to increase the utility flow for durables, a household must trade its current durable good and replace it with a new one. Consistent with this notion, several papers focus on models of lumpy durables adjustment (see, among others, Caballero, 1993; Eberly, 1994). Among these contributions, Leahy and Zeira (2005) is particularly related to our paper, as they study the cyclical effects of the timing of lumpy durable goods purchases in general equilibrium. Recently, Kaplan and Violante (2014), Berger and Vavra (2015), and Guerrieri and Lorenzoni (2017) embed households' fixed adjustment costs in a Bewley (1986)-Huggett (1993)-Aiyagari (1994) general-equilibrium framework with uninsurable idiosyncratic risk. ${ }^{3}$ We enrich this framework with a quality ladder for durables, which households can trade at market-clearing prices on secondary markets (or scrap). ${ }^{4}$ We obtain that the illiquidity of durable goods is an equilibrium outcome that varies with the aggregate state of the economy, rather than a fixed parameter. ${ }^{5}$ Moreover, we show that this

3. Relatedly, Huo and Ríos-Rull (2016) and Favilukis et al. (2017) study the effects of financial shocks in models of housing with incomplete markets.

4. Caplin and Leahy (2006) develop a tractable equilibrium model of durable goods markets with fixed adjustment costs by approximating the distribution of durable goods holdings.

5. We use the term "illiquidity" to relate our framework to the early contribution of Grossman and Laroque (1990), as well as the more recent literature on two-asset incomplete-markets models, such as Kaplan and Violante (2014). In these models, households solve a portfolio problem between a standard asset and an "illiquid" asset—i.e., an asset subject to transaction costs. These papers do not feature illiquidity in the sense of search frictions and related time to sell. Also in our framework, there are no search frictions. However, the cost of adjusting the stock of durable goods is determined by equilibrium prices in a competitive secondary market, as well as standard transaction costs. Prices vary in response to aggregate shocks, because durable goods of different qualities are imperfect substitutes. 
endogenous illiquidity is essential in accounting for the positive comovement of car scrappage and new-car sales observed during the Great Recession. ${ }^{6}$

Second, because of our assumption of indivisibility, our mechanism shares some features with other papers in which agents are simultaneously buying and selling assets. Stein (1995) builds a housing-market model in which households' down-payment constraints amplify shocks to house prices, thereby reducing housing demand. Anenberg and Bayer (2020) show that the cost of simultaneously holding two homes varies endogenously over the cycle, driving fluctuations in trade volume. Garriga and Hedlund (2020) study housing markets in the Great Recession, using an incomplete-markets model with search frictions that render housing illiquid. Our article differs from these contributions in that our equilibrium notion of illiquidity stems from the imperfect substitutability across durables of different qualities that trade at market-clearing prices. Vehicles represent an ideal setting to measure relative price movements across goods of different qualities. However, the main insights from our analysis should also apply to housing markets, as households move up and down a "property ladder.” Relatedly, Ortalo-Magné and Rady (2006) show how housing market dynamics depend on the ability of young buyers to afford the down payment on a house and Landvoigt et al. (2015) emphasize spillover effects across partially segmented housing markets during the 2000-5 housing boom.

Third, the literature on consumer durable goods has investigated the role of secondary markets in allocating new and used goods (see, among others, Rust, 1985; Anderson and Ginsburgh, 1994). Most closely related are the empirical/quantitative papers of Adda and Cooper (2000), who study how government subsidies for the replacement of old cars with new ones in France affect the time-series of new-vehicle sales; Stolyarov (2002), who investigates resale rates across different car vintages; and Gavazza et al. (2014), who provide a quantitative welfare analysis of secondary markets. ${ }^{7}$ We contribute to this literature by introducing (other) incomplete asset markets and macroeconomic shocks, and thus study the interactions between markets for durables and the rest of the economy.

The article also contributes to the literature that studies capital replacement and, more generally, markets for capital goods. Among other papers, Cooper and Haltiwanger (1993) show that the replacement of depreciated machines can create endogenous fluctuations in the productivity and output of a single producer; Cooper et al. (1999) explore aggregate investment fluctuations due to plants' discrete replacement of their capital stock. However, none of these papers consider equilibrium in the market for used capital in the presence of aggregate dynamics and, thus, fluctuations due to endogenous changes in the resale price of capital. Hence, our article complements the recent work of Lanteri (2018), who studies capital reallocation in an equilibrium model of firm dynamics with endogenous resale price of capital, whereas we focus on consumer durables. A key novelty of our framework is that because households simultaneously buy higherquality, new durable goods and sell lower-quality, used goods, price dynamics in the secondary market affect the timing of household purchases in the primary market.

Finally, our mechanism of delayed upgrading of durable goods during the Great Recession is consistent with the concurrent analysis of Dupor et al. (2018), who study the effect of households' income expectations on their car purchases during the Great Recession, and with the evidence

6. Our article is also related to Adda and Cooper (2006), who empirically study the aggregate dynamics of car sales; Oh (2019), who studies durable replacement and second-hand markets in a representative-agent business-cycle model; Rampini (2019), who analyses how durability affects durable-goods financing in a model with collateral constraints; and Chafwehé (2017), who considers secondary markets for durables in a stationary partial-equilibrium model with incomplete markets.

7. Chen et al. (2013) study the effects of the secondary market for automobiles on manufacturers' incentives in the primary market. 
of Jaimovich et al. (2019), who show that households also traded down in the quality of their non-durable consumption in that period.

\section{EMPIRICAL PATTERNS}

The goal of this section is to document key empirical facts on households' adjustment of their vehicle stock and on vehicle prices during the Great Recession. Supplementary Appendix A describes our data and methodology in more detail and provides additional patterns that complement those that we report in this section.

\subsection{Vehicle scrappage decreased}

We obtain the yearly aggregate stock of registered vehicles in the U.S. from the Federal Highway Administration (2017), the yearly inflow of sales of new vehicles from the U.S. Bureau of Economic Analysis (2017), and the yearly inflow of new-vehicle leases from the National Automobile Dealers Association (2015). We combine these sources to construct the yearly outflow of vehicle scrappage using the accounting identity:

$$
\text { SCRAPPAGE }_{t}=\text { STOCK }_{t}-\text { STOCK }_{t-1}+\text { NEW SALES } t+\text { NEW LEASES }_{t} .
$$

Figure 2 displays the resulting series of vehicles scrapped in the U.S. for the period 200514 , and shows that vehicle scrappage bottomed out during the Great Recession, declining by approximately $16 \%$ in 2009 relative to 2007 . Together, Figures 1 and 2 imply that the total stock of vehicles remained approximately constant during the period, whereas the age of the stock increased during the recession, as we document in Supplementary Appendix A.

\subsection{The cost of replacing a used vehicle with a new one increased}

We use data on new-vehicle transaction prices obtained from Dominion Dealer Solutions (2019) (Dominion dataset) and used-vehicle prices obtained from the National Automobile Dealers Association (2016) (NADA dataset) to compute the replacement cost of new vehicles, calculated as the difference between the transaction price of a new (i.e.

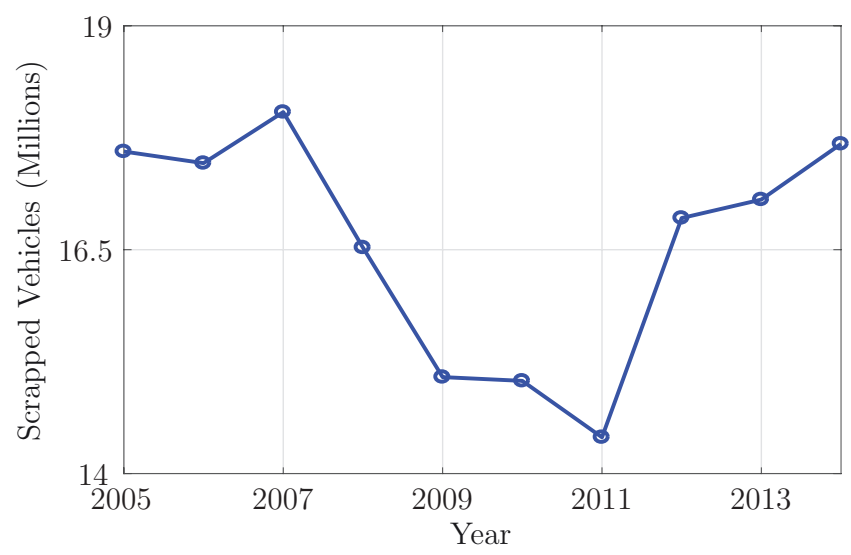

FIGURE 2

Number of vehicles scrapped during 2005-14. 

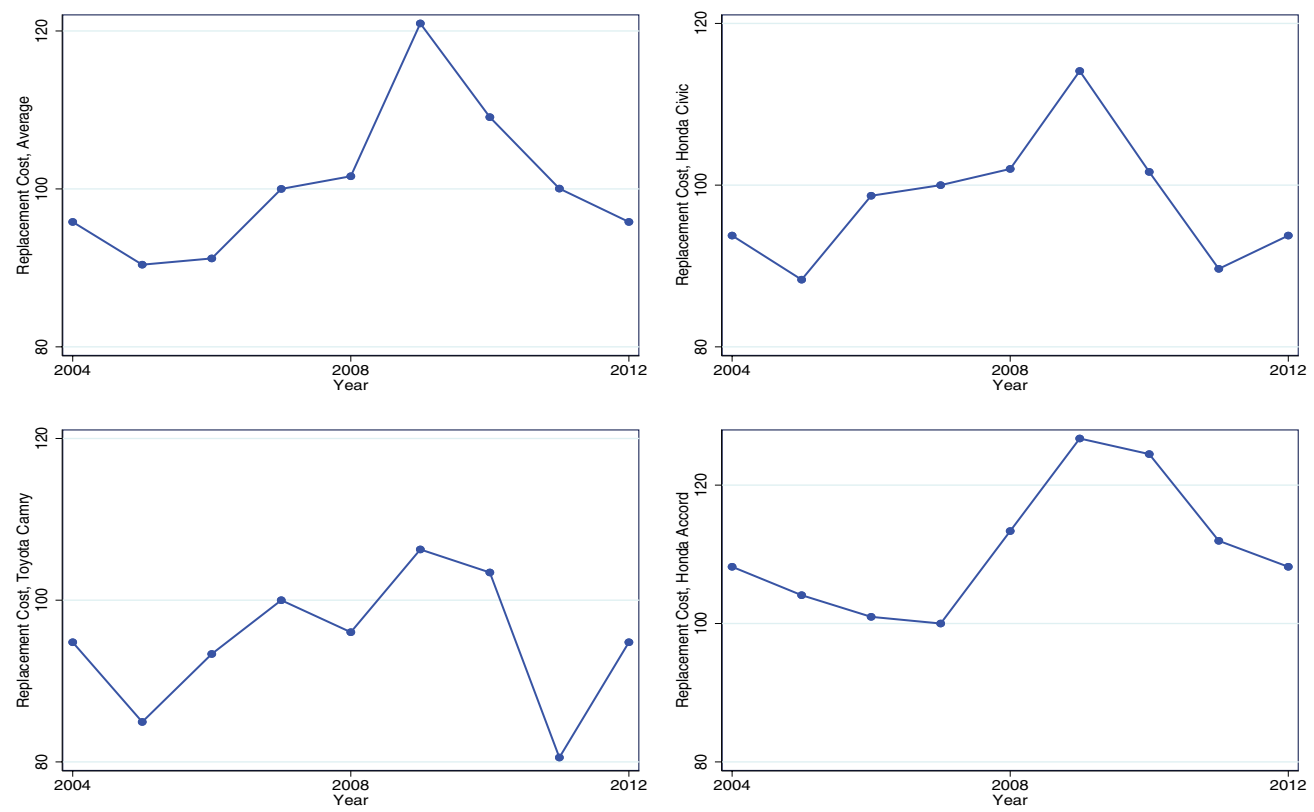

FIGURE 3

The figure displays the linearly detrended (=year 2004) cost of replacing a 4-year-old vehicle with a new one of the same model during the period 2004-12. The top-left panel displays the average cost computed using all vehicles in the Dominion and NADA datasets. The other panels display the costs of replacing three popular models: the Honda Civic (top-right panel), the Toyota Camry (bottom-left panel), and the Honda Accord (bottom-right panel). All series are normalized to equal 100 in 2007.

age-0) vehicle model and the 4-year-old trade-in price of the same vehicle model. The four panels of Figure 3 display these replacement costs. The top-left panel displays an index of replacement costs, which we construct by pooling all vehicles in the Dominion and NADA datasets, normalized to equal 100 in 2007; the other panels portray it for three popular vehicles in the U.S.: the Honda Civic (top-right panel), the Toyota Camry (bottom-left panel), and the Honda Accord (bottom-right panel). All of these panels show that the cost of replacing a used vehicle with a new one spiked during the Great Recession, increasing in 2009 by approximately $20 \%$ relative to pre-recession years. ${ }^{8}$

Figure 4 highlights the main reason why the cost of replacement increased during the Great Recession. The top-left panel displays its two components: the average price of a new and that of a 4-year-old vehicle in our datasets, both normalized to equal 100 in 2007 . This panel shows that while new-vehicle prices displayed a modest average decline of approximately 2-3\% during the Great Recession, used-vehicle prices were substantially more volatile, dropping by slightly more than $20 \%$ during those years. The other three panels portray the price of a new and that of a 4-year-old vehicle for the same models for which Figure 3 displayed the costs of replacement. These panels reveal that new-vehicle price declines were heterogeneous across models, since the prices of a new Honda Civic and a new Toyota Camry exhibit larger reductions than that of a

8. As we explain in Supplementary Appendix A, the NADA dataset reports used-vehicle prices recorded in July of each year (hence, 2008 prices do not incorporate the events of Fall 2008 following the bankruptcy of Lehman Brothers). For consistency, we performed a robustness check that uses new-vehicle transactions that occurred during July of each year only, and the results are very similar to those reported in Figures 3 and 4. 

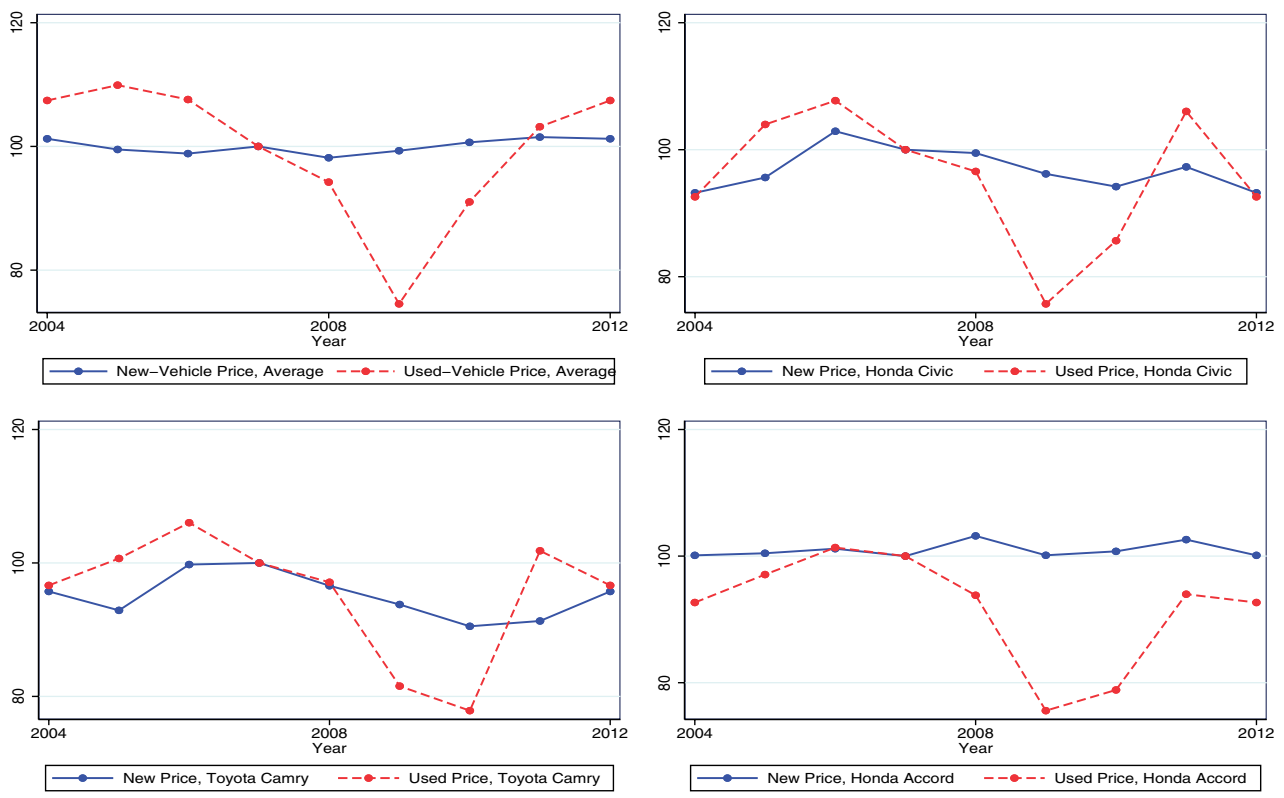

FIGURE 4

The figure displays linearly detrended (=year 2004) prices of new and used (i.e. 4-year-old) vehicles during the period 2004-12. The top-left panel displays the average new price and the average used price computed using all vehicles in the Dominion and NADA datasets, respectively. The other panels display new and used prices of three popular models: the Honda Civic (top-right panel), the Toyota Camry (bottom-left panel), and the Honda Accord (bottom-right panel).

All series are normalized to equal 100 in 2007.

new Honda Accord during the Great Recession. However, all of these models exhibit larger declines in used-vehicle prices than in new-vehicle prices. ${ }^{9}$

In Supplementary Appendix A, we report on two complementary patterns. First, we verify that the Consumer Price Index (CPI) for new- and used-vehicle prices display patterns similar to those in Figures 3 and $4 .{ }^{10}$ Second, we analyse financing incentives (i.e. cash rebates) available to consumers published in the magazine Ward's AutoWorld, showing that they did not increase substantially during the Great Recession. While we do acknowledge that our evidence on financing incentives is limited, we should point out that several papers assert that auto-financing terms did not improve during 2008-9. Most notably, Benmelech et al. (2017) and Ramcharan et al. (2016) show that disruptions in asset-backed securities (ABS) markets led to a deterioration of autofinancing terms for households. Similarly, Gertler and Gilchrist (2018) and Bernanke (2018), among others, review the evidence on financial factors during the Great Recession and maintain that the costs of auto loans increased during those years. ${ }^{11}$

9. Our data suggest that cheaper vehicles experienced larger percentage increases in their replacement cost than expensive vehicles during the Great Recession.

10. We also verified that the starting point of our empirical analysis, i.e., the pre-recession years, were not unusual years for car markets. In particular, both aggregate sales and the CPI price indices for vehicles do not display significant deviations from their long-run trends.

11. Furthermore, the CPI of leased cars and trucks increased during the Great Recession. This additional evidence bolsters the argument that the replacement cost increased and suggests that financing terms did not improve in those years, 


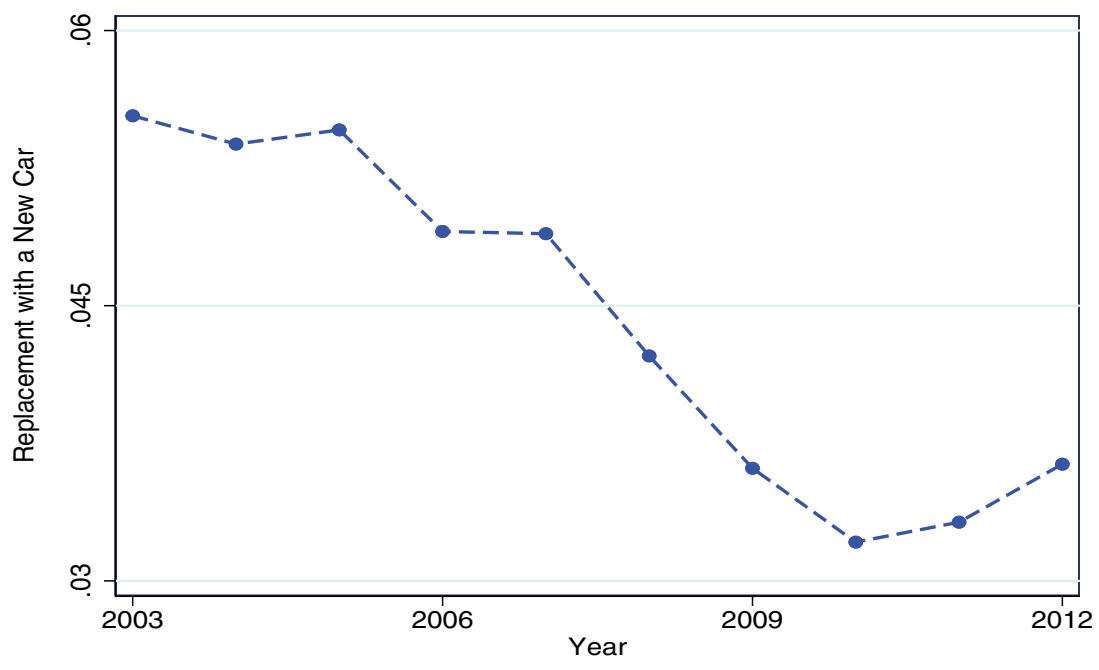

FIGURE 5

Share of households that replaced at least one used vehicle with a new one during 2003-12.

\subsection{Vehicle replacement decreased}

We use the Consumer Expenditure Survey (U.S. Bureau of Labor Statistics, 2013) (CEX) to measure households' vehicle replacement. CEX data are well suited for this purpose, because they report information about households' vehicles, including their acquisition date and whether they were acquired new or used.

We use these data for two main purposes. First, we seek to understand the quantitative importance of replacement for new-vehicle sales by calculating the share of households that replaced used vehicles with new ones, among all households that acquired new vehicles. This share equals approximately 50\% (in Supplementary Appendix A, we explain that this estimate is likely a lower bound of the actual share) and thereby suggests that a decline in replacement can have a first-order effect on new-vehicle sales. Second, we compute the share of households that replaced a used vehicle with a new one. Figure 5 displays this share for each year during 2003-12, showing that it bottomed out during the Great Recession-and thus exactly when the cost of replacement spiked—and recovered thereafter. ${ }^{12}$

Overall, these empirical patterns seem to suggest the following narrative for the decline in newvehicle sales during the Great Recession: households delayed scrapping their (old) cars, thereby decreasing the demand for used cars and depressing their price; in turn, the decline in used-car prices increased the cost of replacing used cars with new ones, thereby reducing the demand for

for two main reasons: (1) Lease rates should be closely related to the replacement cost index that we construct above and display in Figure 3. Specifically, in a frictionless market, the lease rate $l_{i, t, s}$ of vehicle $i$ at time $t$ and duration $s$ should equal $l_{i, t, s}=p_{i, t}-\frac{1}{(1+r)^{s}} E_{t}\left(p_{i, t+s}\right)$, where $p_{i, t}$ is the price of vehicle $i$ in period $t, r$ is the interest rate, and $E_{t}\left(p_{i, t+s}\right)$ is the expected resale value at the end of the lease in period $t+s$ (Gavazza, 2010). (2) Car leasing is a popular form of car financing. More generally, the financing of car leases is very similar to that of auto loans, as both are mostly financed through ABS.

12. Gradual technological progress makes vehicles more durable over time, also inducing a lower-frequency downward trend in the frequency of replacement, as well as positive growth in average vehicle age, as we show in Supplementary Appendix A. 
new cars. ${ }^{13}$ In the next section, we formalize this idea in an incomplete-markets economy in which households can acquire durable goods of different qualities, subject to a borrowing constraint. We show that a tightening of the borrowing limit induces a larger fraction of constrained, lower-income households to decrease their demand for used cars, thereby triggering a decrease in secondarymarket prices; this decrease leads to an increase in the cost for higher-income households to replace their used cars with new ones, and thus decreases new-car sales. ${ }^{14}$

\section{MODEL}

We build a framework to study households' durable adjustment when their durables depreciate over time and they face uninsurable, idiosyncratic income risk. Households derive utility from a non-durable consumption good and a durable good (i.e. a car). The key features of our framework are: (1) durable goods are indivisible and vertically differentiated in their quality, stochastically moving down a quality ladder because of depreciation; (2) used cars trade on quality-specific secondary markets at equilibrium prices, and cars of sufficiently low quality are endogenously scrapped.

In this section, we describe the stationary equilibrium of the model, in which all aggregates and prices are constant over time; in Section 5, we calibrate the model and describe its key quantitative properties; in Section 6, we consider the effects of aggregate shocks.

\subsection{Environment}

Preferences. A continuum of unit-mass of infinitely lived households, indexed by $i$, has preferences represented by a utility function defined over infinite sequences of non-durable consumption $c_{i t}$ and durable consumption (i.e. car services) $d_{i t}$ :

$$
\mathrm{E}_{0} \sum_{t=0}^{\infty} \beta^{t} u\left(c_{i t}, d_{i t}\right),
$$

where $\mathrm{E}_{0}$ is the expectation operator, $\beta \in(0,1)$ is the discount factor, and $u\left(c_{i t}, d_{i t}\right)$ is the per-period utility function.

Durable goods. We consider a finite number $N$ of different car qualities $q_{n}$, with $q_{1}>q_{2}>\ldots>q_{N}$. New cars are of quality $q_{1}$ and cars depreciate stochastically over time. Specifically, a car of quality $q_{n}$, for $n=1, \ldots, N-1$, becomes a car of quality $q_{n+1}$ in the following period with probability $\pi_{n}$. Because we assume that cars of quality $q_{N}$ are useless, our model features positive correlation between car quality and car durability. ${ }^{15}$

13. A further test of this mechanism would exploit cross-sectional heterogeneity in changes in used-car prices across households to estimate how individual households' probabilities of replacing their used cars with new ones depend on the replacement cost. Richer datasets that combine household information on income and wealth with more detailed information about car ownership may allow this analysis to be performed in the future.

14. Supplementary Appendix A reports that households substituted to cheaper new vehicles during the Great Recession. However, the magnitude of this substitution across new cars seems small, most notably when we compare it with the drop in the quantity of new cars sold and the drop in used prices. Hence, this comparison between magnitudes seems to support our choice to focus on the bigger margin of adjustment, namely, whether to acquire a new car and sell/scrap the current depreciated one, in the presence of active secondary markets for used cars.

15. A stochastic process for car depreciation, with a discrete quality ladder, has several advantages over a deterministic process. First, it separates car age and car quality, thereby allowing heterogeneous car qualities across households conditional on identical car ages, while maintaining a negative correlation between the two in the economy. Second, it smooths the aggregation of household replacement decisions. Third, it reduces the number of markets to clear, which reduces the computational burden, while at the same time still allowing for long-lived durables. 
Cars are indivisible and each household owns at most one car. ${ }^{16}$ Hence, $N+1$ possible car ownership statuses exist, with the first $N$ corresponding to the $N$ car qualities; we refer to the $N+1$ th as the status of a household without a car. In period $t$, household $i$ enjoys utility from its durable $d_{i t}$ according to

$$
d_{i t}=d\left(n, \theta_{i}\right) \equiv \begin{cases}q_{n} & \text { if household } i \text { owns a car of quality } q_{n} \\ \theta_{i} & \text { if household } i \text { does not own a car, }\end{cases}
$$

where $\theta_{i}$ is a household-specific type, constant over time, drawn from a distribution $F_{\theta}(\theta)$, that determines household $i$ 's relative preference for living without a car. Hence, we allow for ex ante heterogeneity in households' net utility enjoyed from a car-for example, because of the heterogeneous distance of households' residence from their workplaces or heterogeneous quality of public transport in the cities where they live, which we take as exogenous.

Income. In every period $t$, each household $i$ receives idiosyncratic stochastic income $w_{i t}$ (denominated in units of the non-durable good), which evolves over time according to a Markov process with transition $F_{w}\left(w_{i t}, w_{i, t+1}\right)$.

Technology. New cars are produced by perfectly competitive firms using a linear technology with the non-durable good as the only input. Let $p_{1}$ be the constant marginal cost of new cars in terms of non-durables. Perfectly competitive firms operate a scrappage technology that gives $p_{N}$ units of the non-durable good for each scrapped car, regardless of its quality. A car of quality $q_{N}$ must be exogenously scrapped in the current period.

Markets. Households can trade cars at equilibrium prices $p_{n}$. Households that sell their cars of quality $q_{n}$ incur transaction costs $\lambda\left(p_{n}\right)$. Technology determines $p_{1}$ and $p_{N}$, whereas cars of quality $q_{n}$ trade at their market-clearing prices $p_{n}, n=2, \ldots, N-1$. For notational convenience, we let $p_{N+1}=0$.

Households can borrow and save by trading one-period non-contingent bonds $b_{i, t+1}$ at their equilibrium price $p_{b}$, subject to a borrowing constraint

$$
b_{i, t+1} \geq \phi,
$$

where $\phi \leq 0$ is the debt limit.

Government. The government issues a constant level of non-contingent bonds $b_{G}$ and imposes lump-sum taxes $\tau$ on all households to finance interest payments on its debt. Hence, the budget constraint of the government is

$$
b_{G}\left(1-p_{b}\right)=\tau .
$$

In Section 7, we study a deficit-financed stimulus policy that subsidizes households' car replacement.

Timing. At the beginning of each period, households receive their income and observe the depreciation shock to their durables. Next, they make trading, production, consumption, and saving decisions. The non-durable good is the numeraire of our economy.

16. We abstract from explicitly modelling horizontal differentiation of new-car qualities, because our main focus is the timing of replacement of used cars and its equilibrium response to aggregate shocks. Moreover, computational tractability prompts us to abstract from the possibility of owning multiple vehicles. Although many U.S. households own more than one vehicle, multiple vehicles do not seem to affect the main mechanism we focus on: delayed replacement. 


\subsection{Household problem}

We now describe households' problem in recursive form. Let $V(b, w, n ; \theta)$ be the value function of a household of type $\theta$ with bond holdings $b$, income $w$, and car quality $q_{n}$. This function satisfies the following Bellman equation:

$$
V(b, w, n ; \theta)=\max _{c, b^{\prime}, \tilde{n}} u(c, d(\tilde{n}, \theta))+\beta \mathrm{E}\left[V\left(b^{\prime}, w^{\prime}, n^{\prime} ; \theta\right) \mid \tilde{n}, w\right],
$$

subject to stochastic transitions for income and car quality, the borrowing constraint (3), and the budget constraint:

$$
c+p_{\tilde{n}}+p_{b} b^{\prime}+\tau=w+p_{n}-\lambda\left(p_{n}\right) \mathcal{I}(\tilde{n} \neq n)+b,
$$

where the indicator function $\mathcal{I}(\tilde{n} \neq n)$ equals one when households trade cars and zero otherwise. The left-hand side of the budget equation (6) reports household expenditures: non-durable expenditures $c$, durable expenditures $p_{\tilde{n}}$ on car $\tilde{n}$, bond purchases $p_{b} b^{\prime}$, and lump-sum taxes $\tau$. The right-hand side reports household resources: income $w$; the proceeds $p_{n}$ of the sale of car $n$, net of transaction costs $\lambda\left(p_{n}\right)$; and bond holdings $b$.

The Bellman equation (5) makes it explicit that household preferences for durables depend on their type $\theta$. Similarly, our notation highlights the fact that the car $\tilde{n}$ households choose could differ from the car $n^{\prime}$ they own at the beginning of the following period, because of depreciation.

The policy functions $b^{\prime}=g_{b}(b, w, n ; \theta)$ and $\tilde{n}=g_{n}(b, w, n ; \theta)$ for future bond holdings and car choice, respectively, solve the dynamic program (5).

\subsection{Stationary competitive equilibrium}

We now define the stationary competitive equilibrium of this economy. Clearing in the bond market requires

$$
\int g_{b}(b, w, n ; \theta) d m(b, w, n ; \theta)=b_{G},
$$

where $m(b, w, n ; \theta)$ is the beginning-of-period stationary cumulative distribution of households over individual states (i.e. bond holdings $b$, income $w$, and car quality $q_{n}$ ) and type $\theta$. The lefthand side is the aggregate net demand for bonds from households, whereas the right-hand side is the level of government debt.

Clearing in the market for cars of quality $q_{1}$ requires

$$
\int \mathcal{I}\left(g_{n}(b, w, n ; \theta)=1\right) d m(b, w, n ; \theta)=\int d m(b, w, n=1 ; \theta)+x,
$$

where $x$ is the endogenous aggregate production of new cars. The left-hand side is the aggregate demand for cars of quality $q_{1}$, which comes from all households whose policy function is to hold a car of quality equal to $q_{1}$ (thus the indicator function $\mathcal{I}$ for their choices). The right-hand side is the aggregate supply of cars of quality $q_{1}$, which is the sum of the equilibrium flow of new production $x$ and of the stock of existing cars of quality $q_{1}$ that did not depreciate from the previous period.

Clearing in the market for cars of a given quality $q_{\bar{n}}$, for $\bar{n}=2, \ldots N-1$, requires

$$
\int \mathcal{I}\left(g_{n}(b, w, n ; \theta)=\bar{n}\right) d m(b, w, n ; \theta) \leq \int d m(b, w, \bar{n} ; \theta) .
$$

The left-hand side is the aggregate demand for cars of a given quality $q_{\bar{n}}$, which comes from all households whose policy function is to hold a car of quality $q_{\bar{n}}$ (thus, the indicator function $\mathcal{I}$ for 
TABLE 1

Parameter values

\begin{tabular}{lcc}
\hline Parameter & Value & Target/source \\
\hline$\alpha$ & 0.95 & Vehicles expenditure share \\
$\beta$ & 0.945 & Interest rate \\
$\gamma$ & 2 & Literature \\
$\rho$ & 0.9 & Literature (PSID) \\
$\sigma_{\epsilon}$ & 0.2 & Literature (PSID) \\
$\phi$ & -1 & Fraction of constrained agents \\
$b_{G}$ & 1.5 & Liquid assets/GDP \\
$\pi_{1}$ & $1 / 3$ & Trade frequency on used market \\
$\pi_{2}$ & 0.1 & Average vehicle life \\
$\pi_{3}$ & 0.5 & Scrappage frequency \\
$q_{1}$ & 1 & Normalization \\
$q_{2}$ & 0.3 & Price depreciation \\
$q_{3}$ & 0.1 & Scrappage of $q_{3}$-cars \\
$\theta$ & $10,1\}$ & Household with car/no car \\
$\operatorname{Pr}(\theta=1)$ & 0.1 & Fraction of households with no car \\
$p_{1}$ & 0.45 & New vehicle price/income \\
$p_{4}$ & 0.036 & Price depreciation \\
$\lambda_{0}$ & 0.03 & Estimate in NADA dataset \\
$\lambda_{1}$ & 0.15 & Estimate in NADA dataset \\
\hline
\end{tabular}

their choices). The right-hand side is the aggregate supply of cars of quality $q_{\bar{n}}$. If households do not scrap any car of quality $q_{\bar{n}}$ in equilibrium, equation (9) holds with equality; if households scrap some cars of quality $q_{\bar{n}}$ in equilibrium, equation (9) holds with strict inequality, and $p_{\bar{n}}=p_{N}$; that is, $q_{\bar{n}}$-cars trade at the scrappage value.

Definition 1 A Recursive Stationary Competitive Equilibrium is (i) a value function $V(b, w, n ; \theta)$ and associated policy functions $g_{b}(b, w, n ; \theta)$ and $g_{n}(b, w, n ; \theta) ;($ ii) a stationary distribution $m(b, w, n ; \theta)$; and (iii) a vector of prices $\left(p_{b}, p_{2}, \ldots, p_{N-1}\right)$, such that

1. $V(b, w, n ; \theta)$ satisfies the Bellman equation (5);

2. The stationary distribution $m(b, w, n ; \theta)$ is consistent with the type distribution $F_{\theta}(\theta)$, the exogenous income and car depreciation shocks, and with household policy functions $g_{b}(b, w, n ; \theta)$ and $g_{n}(b, w, n ; \theta)$;

3. The bond market clears-i.e., equation (7) holds;

4. Car markets clear-i.e., equation (8) determines the flow $x$ of production of new cars, and equation (9) holds.

\section{CALIBRATION}

We now describe our choices of functional forms and parameter values for preferences, income process, credit market, car production, and trading costs. Table 1 reports the numerical values of the parameters.

Preferences. We follow Berger and Vavra (2015) and choose the following per-period utility function: $u\left(c_{i t}, d_{i t}\right)=\frac{\left(c_{i t}^{\alpha} d_{i t}^{1-\alpha}\right)^{1-\gamma}}{1-\gamma}$. We set $\alpha=0.95$ to match the expenditure share on vehicles, which equals approximately 5\%, according to Personal Consumption Expenditure data from the U.S. Bureau of Economic Analysis. We set the curvature of the per-period utility $\gamma=2$, which is within the range Aiyagari (1994) considers. 
A period in the model coincides with a year, consistent with the frequency of our data. Hence, we set $\beta=0.945$, which, along with the calibrated degree of idiosyncratic risk discussed below, results in a real interest rate of approximately $2.5 \%$, thereby matching its 2007 value.

Income. We assume that income follows an $\mathrm{AR}(1)$ process in logs: $\log \left(w_{i, t+1}\right)=\rho \log \left(w_{i, t}\right)+$ $\epsilon_{i, t+1}$. We set the persistence of the process to $\rho=0.9$. The innovations $\epsilon_{i, t+1}$ are i.i.d. across households and over time, normally distributed with mean $-0.5 \sigma_{w}^{2}$ and standard deviation $\sigma_{\epsilon}=$ 0.2, following the estimates of Flodén and Lindé (2001) in Panel Study of Income Dynamics (PSID) data. These parameters imply that mean income equals one-that is, a normalizationand the cross-sectional standard deviation $\sigma_{w}$ of the $\log$ of income equals $\frac{\sigma_{\epsilon}}{\sqrt{1-\rho^{2}}}=0.63$. We further discretize this process with a three-valued Markov chain, using the method of Rouwenhorst (1995).

Bond market. We follow Guerrieri and Lorenzoni (2017) and set the level of government debt to match the ratio of liquid assets to GDP, which equals 1.78 in 2006. Moreover, we set the borrowing constraint $\phi$ to target a fraction of constrained households approximately equal to $10 \%$ consistent with the fraction Kaplan and Violante (2014) report. The resulting value of $\phi=-1$ implies that households can borrow up to the average annual income.

Cars. A large number of car qualities (and thus a large number of endogenous prices) renders computation cumbersome, because our model features rich household heterogeneity as well as aggregate dynamics. Hence, we choose a parsimonious structure for car qualities by setting $N=4$.

We set the values of the depreciation probabilities and of the car qualities to match statistics related to the average lifetime of cars and their average price depreciation reported in Jacobsen and van Benthem (2015), which we briefly report now. Specifically, we set the depreciation probabilities as follows: $\pi_{1}=1 / 3$, which implies that on average, high-quality cars depreciate after 3 years. Accordingly, we refer to the market for quality- $q_{2}$ car as the used market. We set $\pi_{2}=1 / 10$, which implies that on average, cars are of medium quality for 10 years; $\pi_{3}=1 / 2$. These depreciation parameters allow our model to closely match two statistics: the average lifetime of cars, which is approximately equal to 15 years, and the average scrappage rate of 15-year-old cars, which is approximately equal to $10 \%$.

We normalize $q_{1}=1$ and set $q_{2}=0.3$ and $q_{3}=0.1$ (we do not need to specify a value for $q_{4}$, as households scrap these cars). These quality levels, along with the aforementioned depreciation probabilities, allow the model to closely match the price decline of a 3-year-old car and, thus, are consistent with average replacement costs in our car-price dataset. We set the marginal cost $p_{1}$ of producing new cars equal to 0.45 in order to match the ratio of average new-car prices to household income. We set the scrappage value $p_{N}$ to 0.036 to match the average residual value of cars older than 15 years. Given these values for $q_{3}$ and $p_{N}$, some households scrap cars of quality $q_{3}$ in the stationary equilibrium of our model, consistent with the evidence on scrappage rates for old cars. This scrappage of quality- $q_{3}$ cars implies that their price equals $p_{N}$.

Moreover, we parameterize the type distribution that determines the utility of not owning any car to a two-type distribution, with values $\theta_{i} \in\{0,1\}$. Thus, households with $\theta_{i}=1$ choose not to own a car, whereas households with $\theta_{i}=0$ choose to own one. We set the probability distribution over types to match the empirical share of households with no car, which equals approximately $10 \%$ in the 2000-10 American Community Survey.

Transaction costs. We specify the transaction-cost function to include a fixed cost and a cost proportional to the car value- that is, $\lambda_{0}+\lambda_{1} p_{n}$. We use NADA prices to calibrate these parameters to match the difference between retail and trade-in prices across cars of different 
vintages, implying that empirical retail prices map into the prices paid by buyers in the model and trade-in values map into the prices obtained by sellers. We obtain $\lambda_{0}=0.03$ and $\lambda_{1}=0.15 .{ }^{17}$

\subsection{Properties of the stationary equilibrium}

We now describe the main features of the stationary equilibrium of the calibrated model, with a greater focus on durable goods.

Because the utility function displays complementarity between non-durable consumption and durable consumption, households enjoy both a higher level of non-durable consumption and higher-quality cars as their liquid wealth (i.e. bonds $b_{i t}$ ) and income increase. Thus, the correlation between non-durable consumption and car values is positive: It equals 0.51. Similarly, the correlation between liquid wealth and car values equals 0.49 . The presence of transaction costs and the discreteness of the set of car qualities induce inaction in durables adjustment, thereby reducing these correlations relative to their values in models in which households can freely adjust their durable stock. ${ }^{18}$ These correlations are also lower than the correlation between bond holdings $b_{i t}$ and non-durable consumption $c_{i t}$, both of which households can adjust at no cost, and which equals 0.83 . Moreover, the correlation between income $w_{i t}$ and beginning-of-period car values is 0.38 , whereas the correlation between income and the value of the car chosen for the same period $\left(p_{\tilde{n}}\right)$ is higher and equals 0.56 . This difference reflects the fact that income shocks are persistent, and thus provide information about future wealth and consumption, inducing durable adjustment. The correlation between income and non-durable consumption, which is freely adjustable, is 0.88 .

Figure 6 displays households' main replacement policies as a function of their bond holdings (on the vertical axis) and income (on the horizontal axis): The dashed line is the threshold for replacing cars of quality $q_{2}$, and the solid line is the threshold for replacing cars of quality $q_{3}$. These thresholds represent the minimum level of bond holdings that triggers households with a given level of income to upgrade their car. For instance, households with a $q_{2}$-car $\left(q_{3}\right.$-car) upgrade to a higher-quality $q_{1}$ car $\left(q_{2}\right.$ or $q_{1}$ car) if their bond holdings and income lie above the dashed (solid) line, whereas they keep their current car if their bond holdings and their income lie below the dashed line.

The figure identifies three sets of households. The first, above the dashed line, comprises the richest households, who replace their cars as soon as they depreciate from $q_{1}$ to $q_{2}$. In the stationary equilibrium of our economy, approximately $4 \%$ of households upgrade from $q_{2}$ to $q_{1}$ in each period. This moment is close to the empirical fraction of households upgrading from a used car to a new one displayed in Figure 5, even though this is not a calibration target. The second set, between the solid line and the dashed line, comprises mid-wealth households. The majority of these mid-wealth households replace cars of quality $q_{3}$ (or $q_{4}$ ), and buy cars of quality $q_{2}$ from the richest households. The minority of mid-wealth households - that is, those with low liquid wealth and high income-replace their cars of quality $q_{3}$ with cars of quality $q_{1}$ : because the persistence of income shocks is high, these households expect their wealth and non-durable consumption to increase in the near future; thus, they choose to avoid paying the transaction costs multiple times and upgrade directly to cars of the highest quality. In the stationary equilibrium, approximately $2 \%$ of households upgrade directly from a car of quality $q_{3}$ to a car of quality $q_{1}$. The figure shows that the solid threshold for upgrading from $q_{3}$ to a higher-quality car (either $q_{2}$ or

17. This procedure abstracts from other potential sources of trading costs, such as time and search costs, which unfortunately we cannot measure in our data.

18. In Section 6.2, we compute the stationary equilibrium of the economy without transaction costs. This allows us to isolate the separate roles of quality discreteness and transaction costs for the correlation between non-durable consumption and car qualities. 


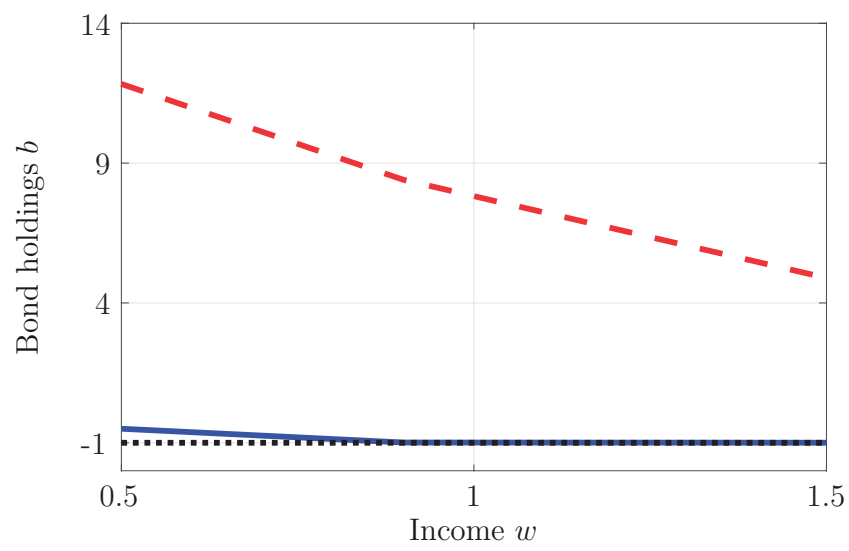

FIGURE 6

Thresholds for car replacement. The solid line represents the threshold for upgrading from quality $q_{3}$ to quality $q_{2}$ (or $q_{1}$, in the case of households with the highest income realization). The dashed line represents the threshold for upgrading from quality $q_{2}$ to $q_{1}$. The dotted line corresponds to the borrowing limit $\phi$.

$q_{1}$ ) coincides with the borrowing limit (i.e. the horizontal dotted line at $\phi=-1$ ) for households with sufficiently high income. The third set, the one above the dotted line of the borrowing limit $\phi=-1$ and below the solid line, comprises households with low income and high debt. These households keep their low-quality cars and will upgrade only after they deleverage and move away from the borrowing constraint. We recall that in our stationary equilibrium, $10 \%$ of households are borrowing-constrained (this fraction is a calibration target). The vast majority of these constrained households-approximately 85\% — have a low income realization and thus are in this third region.

Finally, the stationary equilibrium of the economy features no household that downgrades to lower-quality durables: all households, including those that own cars of quality $q_{1}$, either hold on to their cars or upgrade to higher-quality cars.

\section{MACROECONOMIC SHOCKS}

In this section, we study the effects of macroeconomic shocks, such as an aggregate tightening of the borrowing limit and a negative aggregate income shock. Specifically, we compute the transitional dynamics of our model economy that starts from the steady state characterized in Section 5.1, receives unexpected aggregate shocks (described in more detail in the following sections), and reaches a new steady state over time, thereby following several recent papers that assume households did not foresee the aggregate shocks of the Great Recession (e.g. Huo and Ríos-Rull, 2016; Guerrieri and Lorenzoni, 2017). Along the transition path, we assume that households have perfect foresight about aggregate variables.

When the economy is out of steady state, the value function, the distribution of households over individual states, and the equilibrium prices for bonds and cars change over time. Hence, we solve for the sequences $\left\{V_{t}\right\}_{t=0}^{T},\left\{m_{t}\right\}_{t=0}^{T},\left\{p_{b, t}, p_{2, t}, \ldots, p_{N-1, t}\right\}_{t=0}^{T}$, consistent with household optimization and market clearing, where $t=0$ is the period in which shocks hit and households learn about them, and $T$ is the period in which the economy reaches its new steady state. Supplementary Appendix C describes the numerical algorithm, explaining a novel, widely applicable method we develop to overcome the challenge of clearing multiple markets when heterogeneous agents make discrete choices. 

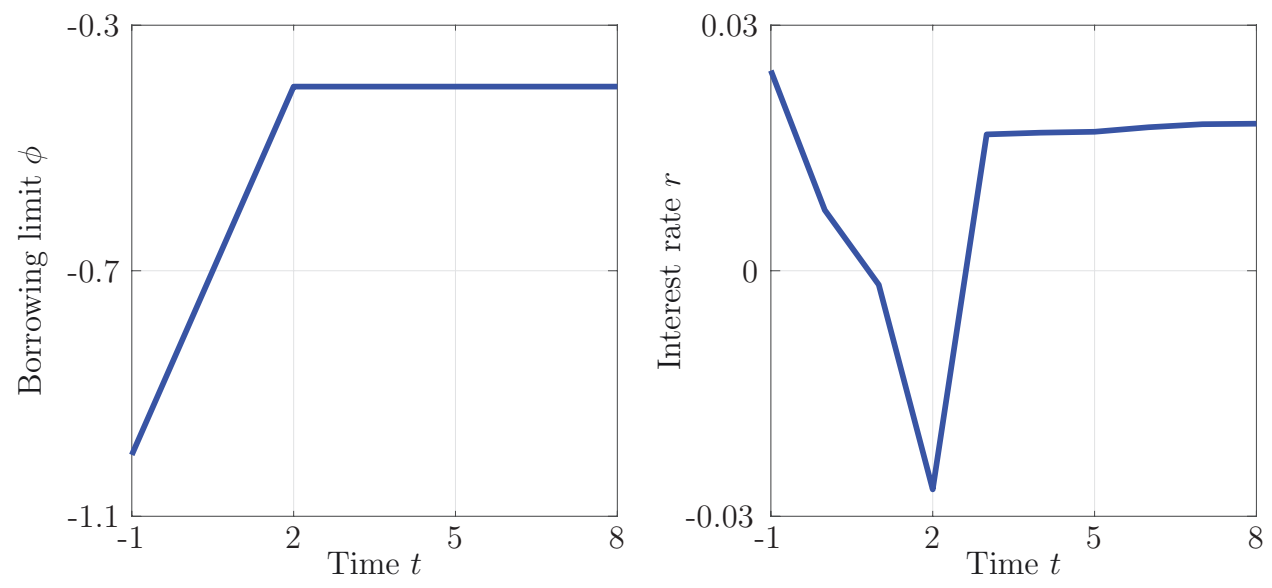

FIGURE 7

The left panel displays the dynamics of the borrowing constraint and the right panel displays the dynamics of the interest rate. The economy is in the stationary equilibrium at $t=-1$, and households learn about the new path of the borrowing limit at $t=0$. The horizontal axis displays time $t$.

We start by considering the effects of a credit shock that tightens households' borrowing limit. In our view, this case allows us to illustrate in the cleanest way the main economic mechanisms that lead to declines in new-car sales, scrappage, and used-car prices. Moreover, we show that it can quantitatively account for a sizable fraction of the declines observed in the data. We will further enrich the model to include additional realistic features of the Great Recession, such as aggregate income shocks and a borrowing constraint that depends on the value of households' durable holdings - that is, a collateral constraint. These richer versions of the model improve the quantitative performance of the calibrated model.

\subsection{Credit shock}

We now analyse the aggregate dynamics of our economy following a tightening of the borrowing limit for all households. ${ }^{19}$ We model this credit tightening as an unexpected shock that hits the economy in its stationary equilibrium; when the shock hits, households learn about current and future credit limits.

We parameterize the path of the borrowing limit to match the sharp decline in the real interest rate during the Great Recession, which dropped from 2.5\% in 2007 to - $2 \%$ in 2010 (we measure the real interest rate as the difference between the annualized return on 3-month Treasury bills and the growth of the GDP-deflator). In practice, we match this decline by gradually decreasing the credit limit from $\phi=-1$ in the pre-shock stationary equilibrium at $t=-1$ to $\phi_{t}=-0.4$ at $t=2$, thus changing by 0.2 in each period $t=0,1,2$. After the shock the credit limit stays permanently at its new, tighter level, as in Guerrieri and Lorenzoni (2017). ${ }^{20}$

Figure 7 displays the sharp decline in the interest rate (right panel) as the tighter borrowing limit (left panel) changes all households' consumption-saving trade-off. Specifically, the shock

19. Benmelech et al. (2017) and Guerrieri and Iacoviello (2017) emphasize the empirical relevance of aggregate credit-market conditions for vehicle sales.

20. We also consider a persistent, but not permanent, credit shock in Supplementary Appendix B and obtain similar results. 

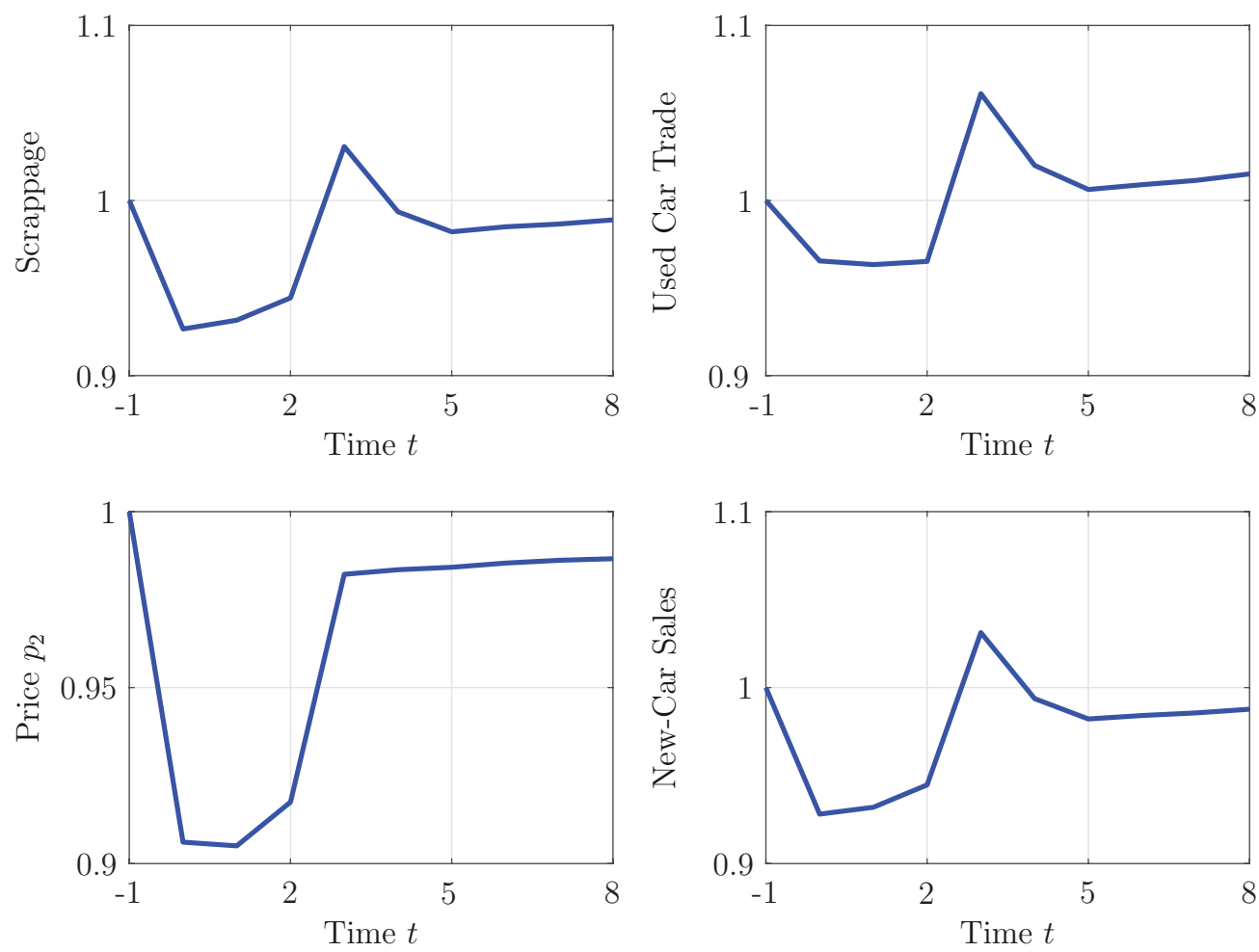

FIGURE 8

Dynamics of the credit shock. The economy is in the stationary equilibrium at $t=-1$, and households learn about the new path of the borrowing limit at $t=0$. The horizontal axis displays time $t$. The top-left panel displays scrappage; the top-right panel the volume of trade of used cars; the bottom-left panel the price $p_{2}$ of quality- $q_{2}$ cars; and the bottom-right panel the sales of new cars.

forces low-wealth households, whose debt is close to the old borrowing constraint, to reduce their debt to satisfy the new, tighter borrowing limits. Simultaneously, wealthier households seek to increase their precautionary savings, foreseeing that they will face tighter credit conditions in the future should their income decrease. Because the aggregate demand for savings increases, the top-right panel shows that the real interest rate $r_{t} \equiv 1 / p_{b, t}-1$ falls to clear the bond market. The drop in the interest rate is particularly swift when the borrowing limit changes in periods $t=0,1,2$ because households need to satisfy the increasingly tighter borrowing constraints; the interest rate then stabilizes around its new steady state level of $1.9 \%$ - that is, 60 basis point lower than its value of $2.5 \%$ in the old steady state-when the borrowing limit stays at its new long-run level.

Figure 8 displays striking patterns in car markets, most notably while the borrowing limit becomes increasingly tighter in $t=0,1,2$. The credit tightening motivates all households to postpone expenditures on durable goods, thereby holding on to their current cars and delaying their replacement. These incentives are stronger for low-wealth households, as their initial debt was close to the old borrowing limit. Because these households usually own cars of quality $q_{3}$ and postpone their replacement, scrappage falls (top-left panel) and the demand for used cars of 
quality $q_{2}$ falls as well. ${ }^{21}$ The lower demand for cars of quality $q_{2}$ induces a decrease in their trading volume (top-right panel) and equilibrium price (bottom-left panel).

This softening of used-car markets also spurs wealthy households to postpone the replacement of their cars. These households usually own cars of quality $q_{2}$ and would upgrade to new ones in normal times - that is, in the pre-shock stationary equilibrium. However, these wealthy households now face a high replacement cost, because they can trade in their $q_{2}$-cars only at firesale prices; moreover, they anticipate that used-car values will recover after the economy adjusts to the new credit conditions. Hence, new-car sales decline on impact at $t=0$ (bottom-right panel). This finding is striking, because (1) the tighter credit limits are not binding for new-car buyers and (2) the real interest rate falls sharply, which makes durable-goods purchases attractive for unconstrained households.

Quantitatively, the credit shock accounts for declines in new-car sales and in scrappage of approximately 7 percentage points, and in used prices of approximately 10 percentage points relative to their respective values in the stationary equilibrium at $t=-1$. Hence, our quantitative analysis suggests that a credit tightening, disciplined to match the dynamics of the interest rate observed in the data, can account for approximately $20 \%$ of the decline in new car sales and for approximately $50 \%$ of the increase in the replacement cost of used cars that we documented in Sections 1 and 3, respectively. In the following sections, we will show that introducing further realistic features to our model, such as an aggregate income decline, brings the key outcomes of our model economy quantitatively closer to their empirical counterparts.

When the economy recovers from the credit shock, the protracted delay in car replacement prompts a spike in scrappage, used trade, and new sales at $t=3$. In Section 6.5, we will show that these spikes become more muted once we introduce additional features of credit markets, such as collateral constraints. ${ }^{22}$ From $t=4$, car markets gradually adjust to the new stationary equilibrium. $^{23}$

\subsection{Inspecting the mechanism: endogenous illiquidity of durable goods}

A distinctive feature of our model is the endogenous illiquidity of durable goods, which implies that the volume of trade in secondary markets and used-car prices drop as credit constraints tighten. As we recount in Section 2, this endogenous illiquidity is in contrast to a large literature that assumes constant transaction costs, implying that the interest rate is the key price signal for durable purchases. The goal of this subsection is to highlight the differences between our framework and that prevailing in the literature. To do so, we now analyse the equilibrium effects of the credit shock in a series of counterfactual scenarios to disentangle the separate roles of changes in the borrowing limit, equilibrium price changes, and exogenous transaction costs.

The role of equilibrium prices. In this subsection, we provide three sets of counterfactuals that highlight the contribution of equilibrium prices. First, we decompose the results of Figure 8 into the individual contributions of the credit shock, the interest rate, and the price of used cars. Second, we consider a counterfactual scenario in which the credit shock hits the economy and

21. The credit shock also leads to a fall in demand for cars of quality $q_{1}$ from households with low wealth and high income that upgrade directly from $q_{3}$ to $q_{1}$ in the stationary equilibrium.

22. Moreover, car durability has been increasing steadily over time, thanks to long-run technological improvements, lengthening the expected life of vehicles, as we report in footnote 12 and Supplementary Appendix A. While it is challenging to model this trend in a tractable way in our framework, accounting for this long-run trend would likely dampen the spike in new-car sales driven by pent-up demand for replacement.

23. An implication of our assumption of stochastic quality depreciation is that the echo effects of aggregate shocks are quantitatively less important, relative to models of durables replacement with deterministic quality (or age) transitions. 

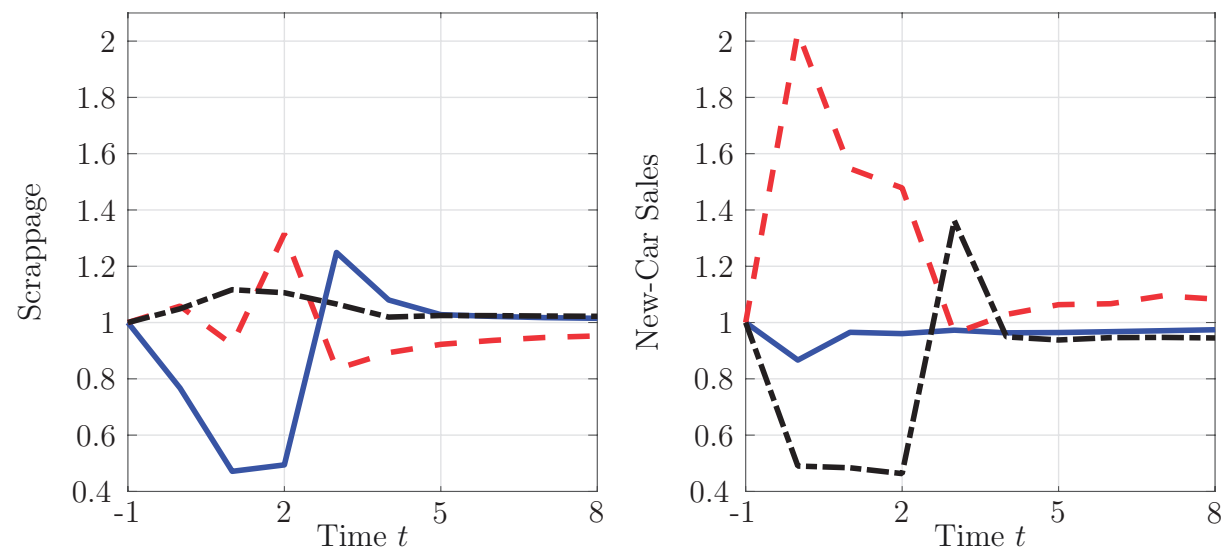

FIGURE 9

Decomposition of the individual effects of credit shock and price changes. The left panel displays scrappage and the right panel sales of new cars. The solid line refers to the effects of changes in the borrowing limit; the dashed line to the effects of equilibrium interest rate dynamics; the dashed-dotted line to the effects of equilibrium used-car price dynamics.

bond markets clear, but used-car prices do not change. Finally, we consider a counterfactual scenario in which the credit shock hits the economy and used-car markets clear, but the interest rate does not change-i.e., a small open economy.

Decomposition: credit limit versus prices. We aim to decompose the direct effects of the credit shock and the equilibrium effects due to price changes by computing the transitional dynamics of scrappage and new-car sales in three different cases, in which we only change: (1) the borrowing limit, (2) the interest rate, and (3) the price of used cars. Figure 9 displays car-market outcomes in these three cases.

Specifically, in the first case (solid line), we feed into the household problem the path of the borrowing limit only - that is, without clearing the bond market through the endogenous interest rate and without clearing the used-car market through the endogenous used-car price. In this case, the economy experiences a massive decline in scrappage, by approximately $50 \%$, and a smaller decline in new-car sales, by approximately $12 \%$.

In the second case (dashed line), we feed into the household problem the path of the interest rate only. In this case, the economy experiences a boom in new-car sales, temporarily doubling, as the decline in the interest rate corresponds to a decline in the user cost of new cars; thus, many households find it optimal to substitute away from bonds and toward high-quality durables. ${ }^{24}$

In the third case (dashed-dotted line), we feed into the household problem the equilibrium path of the price of quality- $q_{2}$ cars only. In this case, the economy experiences an increase in scrappage and a large decline in new-car sales, by approximately 50\%, since low-wealth households scrap their low-quality cars and upgrade to intermediate-quality cars, whereas high-wealth households face a sharp increase in the cost of replacing their $q_{2}$ cars with higher-quality, new ones. ${ }^{25}$

24. In Supplementary Appendix B, we explicitly relate our mechanism to the notion of user cost of a durable good.

25. Because we consider a permanent credit shock, each item of this decomposition has a terminal condition that differs from the initial condition. For instance, when we change the borrowing limit only, the terminal household value function depends on the initial stationary-equilibrium prices and on the final stationary-equilibrium borrowing limit, thereby combining short-run effects and long-run differences. In order to isolate the short-run effects, in Supplementary 
This decomposition sheds further light on the general-equilibrium dynamics displayed in Figure 8. Overall, it suggests that the credit shock plays a key role for scrappage, as it directly affects low-wealth households' choices; the secondary-market equilibrium transmits the shock from low-wealth households' scrappage decisions to high-wealth households' upgrades of their durable goods. This equilibrium feedback from the used-car market to the new-car market dominates the effect of the decline in the interest rate on new-car purchases, which instead makes car replacement more desirable by reducing the user cost of new vehicles.

No equilibrium in secondary markets. To further highlight the role of secondary markets, we now consider the following partial-equilibrium counterfactual scenario. We assume that the credit limit tightens and the bond market clears; however, durable-goods prices do not adjust. Specifically, we assume that households can transform durable goods into non-durable goods (and vice versa) at constant rates of transformation, equal to the prices prevailing in the initial stationary equilibrium. Hence, while the interest rate adjusts to clear the bond market after the credit tightening, the price $p_{2}$ of used cars is constant along the transition.

The left panel of Figure 10 displays the path of car scrappage and the right panel displays the path of new-car sales in this partial-equilibrium case. In the absence of the endogenous response of used-car prices, the economy features a strong negative comovement between scrappage and newcar purchases. This comovement arises because borrowing-constrained households still decide to postpone scrappage of their low-quality cars, as the left panel shows. Their demand for used cars falls, but in the absence of secondary-market clearing, this shift in demand does not translate into a lower price for used cars; hence, wealthy households experience no change in the cost of replacing their used $q_{2}$ cars with higher-quality ones. In addition, the decrease in the real interest rate stimulates their car-replacement activity, inducing a large increase in new-car salesapproximately equal to $60 \%$-relative to their value in the initial stationary equilibrium, as the right panel shows. ${ }^{26}$

This counterfactual case indicates that equilibrium in secondary markets plays a key role in generating a decline in purchases of new durables and a positive comovement of scrappage and new sales, consistent with the U.S. data during the Great Recession we reported in Sections 1 and 3.

We now further investigate the dynamics of the aggregate stock of cars in this counterfactual experiment. Because many wealthy households respond to the interest-rate decline by upgrading to cars of quality $q_{1}$, whereas many poorer households tend to hold on to cars of quality $q_{3}$, instead of upgrading to $q_{2}$, because of the tighter credit limit, there are effects of opposite signs on the average quality of cars. Thus, we compute the aggregate quality of the stock of cars as follows: $Q_{t} \equiv \sum_{n=1}^{N} m_{n t} q_{n}$, where $m_{n t}$ is the fraction of households who own a car of quality $n$ at the beginning of period $t$, which we obtain by integrating the distribution of households over wealth and income. As we display in Figure 11, aggregate durables quality $Q_{t}$ increases in response to the credit shock. This result clarifies that the effects of precautionary savings and interest-rate changes on the production of new cars dominate the effects of the decisions of poorer households and the associated decline in transitions to quality $q_{2} \cdot{ }^{27}$

Appendix B, we also consider a temporary, but highly persistent, credit shock, since the temporary shock removes the effects of long-run differences in steady-state values. We find that our key results are robust to this change. Notably, secondary markets account for the entirety of the decline in new-car sales in this alternative scenario.

26. The increase in purchases of durable goods in response to a credit tightening is consistent with some of the findings of Guerrieri and Lorenzoni (2017), most notably their Figure 15.

27. The variable $Q_{t}$ is the relevant counterpart of the aggregate stock of durables in models that do not explicitly distinguish between heterogeneity in quality or quantity. For completeness, we also verified that the aggregate value of 

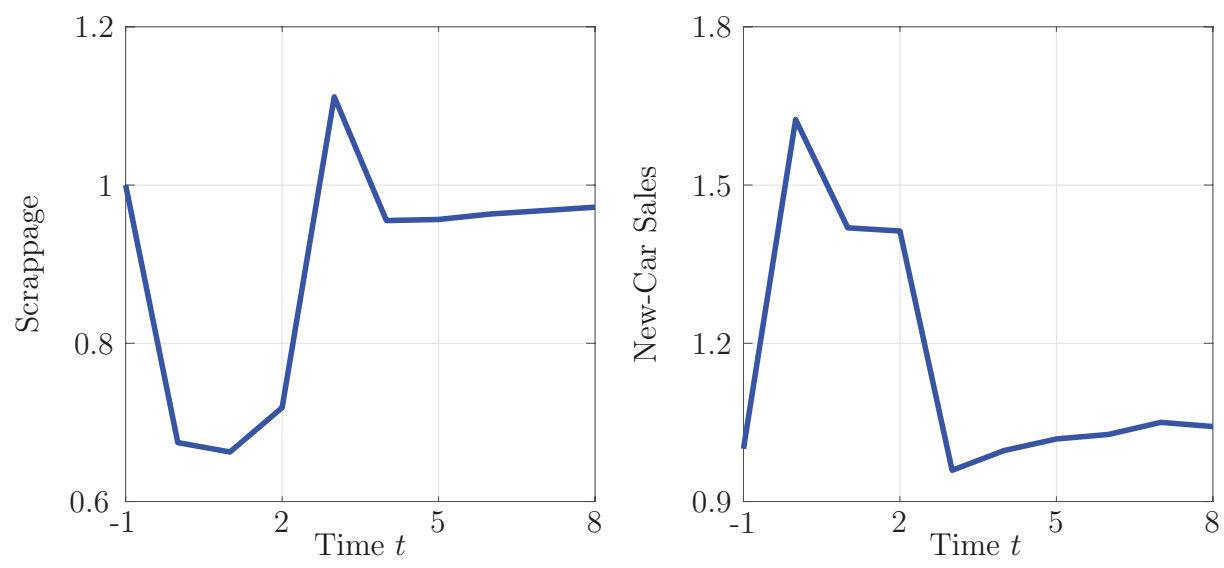

FIGURE 10

The effect of the credit shock on car markets in the absence of used-car market clearing. The economy is hit by the same credit shock as in Figure 8. The bond market clears. However, the market for used cars does not clear-that is, cars can be re-transformed into non-durable consumption at the prices prevailing in the initial stationary equilibrium. The left panel displays scrappage and the right panel displays sales of new cars.

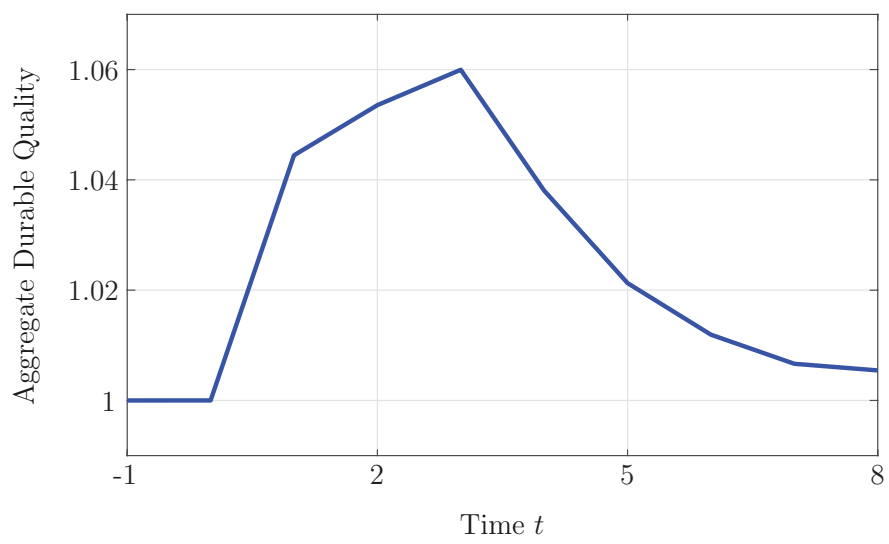

FIGURE 11

The effect of the credit shock on aggregate quality of the car stock in the absence of used-car market clearing. The economy is hit by the same credit shock as in Figure 8. The bond market clears. However, the market for used cars does

not clear-that is, cars can be re-transformed into non-durable consumption at the prices prevailing in the initial stationary equilibrium. The figure displays the aggregate quality of the stock of cars, $Q_{t} \equiv \sum_{n=1}^{N} m_{n t} q_{n}$, where $m_{n t}$ is the fraction of households who own a car of quality $n$ at the beginning of period $t$.

In this counterfactual analysis, we have assumed that a technology allows to transform durable goods into non-durables at constant rates equal to stationary-equilibrium prices, thus removing the effects of imperfect substitutability of durable goods on endogenous price changes. In Supplementary Appendix B.2, we also investigate an alternative assumption that makes durable 
goods of different qualities perfect substitutes by changing household preferences. Specifically, we remove the assumption of indivisibility and let households purchase any positive amounts of durable goods of different qualities.

Consistent with our baseline model with indivisibility, we find that poorer household demand lower-quality cars. Hence, credit shocks affect demand for used cars and market-clearing in the secondary market plays an important role in transmitting them to the production of new cars. Different from the counterfactual experiment with a re-transformation technology for durables, we find that perfect substitution in preferences does not necessarily imply that relative prices of durables of different qualities are constant. Durable goods prices depend both on quality, which affects the utility flow, and on discounted residual value, and thus are jointly determined with the equilibrium interest rate.

Small open economy. We now analyse the interaction between the endogenous real interest rate and our mechanism of endogenous illiquidity based on equilibrium in the secondary market. To this end, we consider a small-open-economy version of our model that keeps the interest rate exogenously constant at its initial stationary-equilibrium value. We hit the economy with the same credit shock as in the baseline case and impose equilibrium in used-car markets only. We then compare the small-open-economy outcome with the general-equilibrium outcome-that is, the case in which both interest rates and car prices adjust to clear their respective markets.

Figure 12 displays this comparison: the solid lines refer to the general-equilibrium model and the dashed lines to the small open economy. We find that our mechanism linking the credit shock to new-car sales through used-car prices is highly powerful in the small open economy: a $4 \%$ decline in used prices leads to a drop in new sales of approximately $40 \%$. The decline in new sales is similar to its empirical counterpart, whereas the decline in used-car prices in the small-open-economy model is five times smaller than its empirical counterpart of $20 \%$.

Relative to these small-open-economy dynamics, the endogenous decline in the interest rate adds two key effects. First, a temporarily low real rate stimulates durable upgrading for highwealth households, that face a portfolio decision between bonds and durable goods. Because of this decline in the interest rate, the decline in new-car sales in response to the credit shock is more moderate in the general-equilibrium case than in the small-open-economy case. Second, new-car purchases triggered by a low interest rate represent an outward shift in the supply of used cars, as new-car buyers trade in their used cars. This outward supply shift creates additional downward pressure on used-car prices. Hence, we find that the magnitude of the decline in $p_{2}$ is twice as large in the general-equilibrium case as in the small-open-economy case, and closer to the magnitude observed in the data.

The comparison displayed in Figure 12 suggests that endogenous changes in the real interest rate likely played a consequential role in the large decline in used-car prices during the Great Recession, while attenuating the elasticity of new-car sales to used-car prices. These cross-market equilibrium effects are a novel feature of our framework, and they highlight the importance of modelling durable-goods dynamics in general equilibrium.

In Supplementary Appendix B.3, we leverage the small-open-economy version of our model to implement two alternative calibration strategies of the credit shock that target household debt statistics reported by the Consumer Financial Protection Bureau, rather than targeting the dynamics of the real interest rate, as in our baseline calibration. Specifically, in one alternative calibration, we target outstanding auto loans; in the other calibration, we target overall household debt. We find that our mechanism plays a key role in both alternative calibrations. Quantitatively, the effects of the shock on new-car sales are large and similar to those of our baseline case when we match auto loans, but weaker when we consider overall household debt. This difference arises 

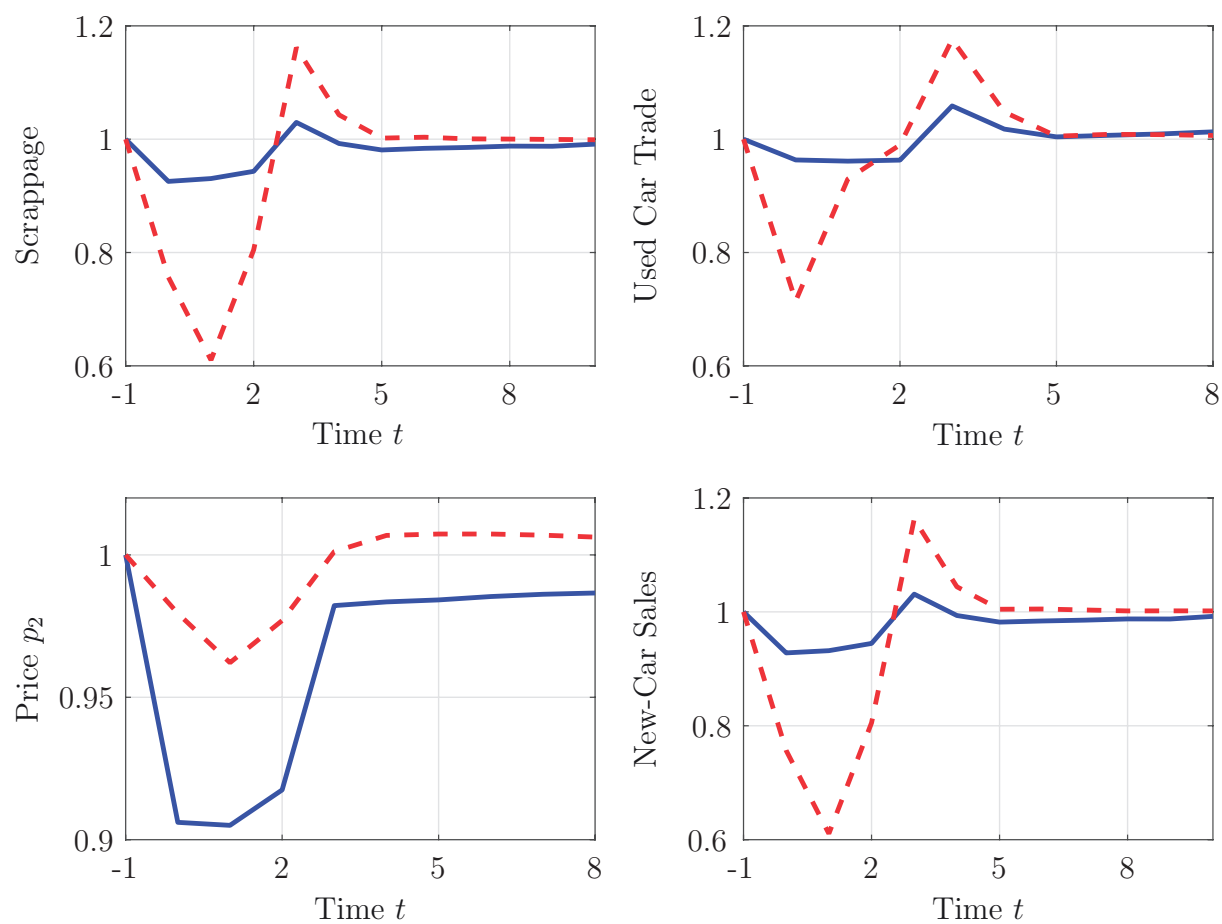

FIGURE 12

Dynamics of the credit shock in a small open economy. The economy is in the stationary equilibrium at $t=-1$, and households learn about the new path of the borrowing limit at $t=0$. The horizontal axis displays time $t$. The top-left panel displays scrappage; the top-right panel the volume of trade of used cars; the bottom-left panel the price $p_{2}$ of quality- $q_{2}$ cars; and the bottom-right panel the sales of new cars. The solid line displays the general-equilibrium case-i.e., market clearing in bond market and car markets. The dashed line displays the small-open-economy case-i.e., market clearing only in car markets.

because outstanding mortgages declined gradually in the data, calling for a small and gradual credit shock in the model.

The role of transaction costs. A large literature emphasizes the role of transaction costs in explaining consumer inertia in durable-goods markets (e.g. Caballero, 1993; Attanasio, 2000; Berger and Vavra, 2015). We now study how transaction costs affect our economy and its response to the credit shock. To this end, we remove transaction costs by setting $\lambda_{0}=\lambda_{1}=0$. We first describe the key patterns of car replacement in the stationary equilibrium to facilitate comparison with the stationary equilibrium of the economy with transaction costs of Section 5.1; we then discuss the response of this economy to the credit shock.

As we recount in Section 5.1, the stationary equilibrium of the economy with transaction costs features no households downgrading the quality of their cars, and approximately $4 \%$. of households replacing cars of quality $q_{2}$ with cars of quality $q_{1}$. These patterns change significantly in an economy with no transaction costs. First, $1 \%$ of households downgrade from $q_{1}$ to $q_{2}$. Second, $0.3 \%$ of households downgrade from $q_{2}$ to $q_{3}$. Third, the volume of trade of used cars is higher: more than $7 \%$ of households replace a car of quality $q_{2}$ with a car of quality $q_{1}$. Overall, these patterns of trading increase the correlation between non-durable consumption and 

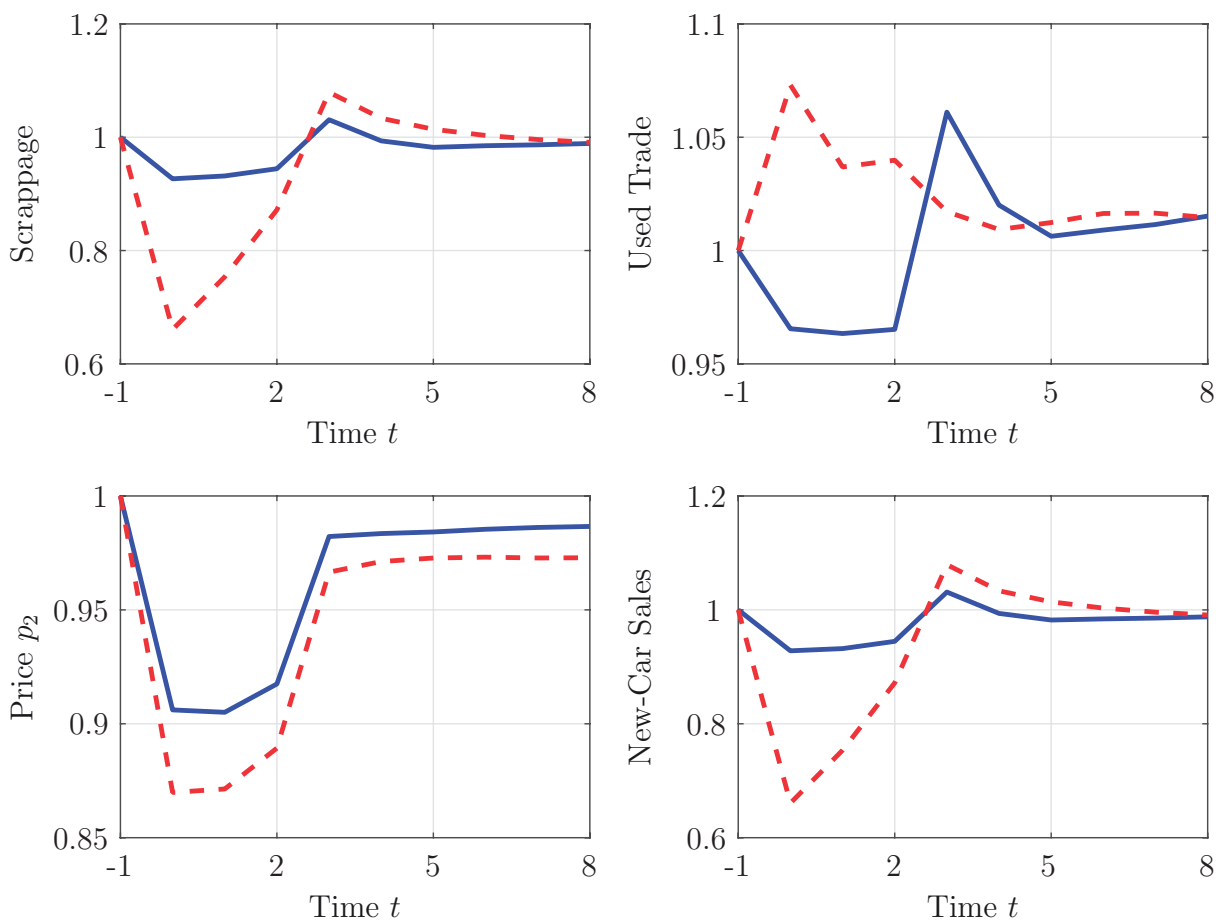

FIGURE 13

Credit shock in the absence of transaction costs. The economy is in stationary equilibrium at $t=-1$. Households learn about the new path of the borrowing limit $t=0$. The horizontal axis displays time $t$. The top-left panel displays scrappage; the top-right panel the volume of trade of used cars; the bottom-left panel the price $p_{2}$ of quality- $q_{2}$ cars; and the bottom-right panel the sales of new cars. The solid line displays the baseline case and the dashed line displays the case without transaction costs $\left(\lambda_{0}=\lambda_{1}=0\right)$.

car values: this correlation coefficient equals 0.66 , versus 0.49 in the economy with transaction costs.

The absence of transaction costs implies that quality downgrading plays an important role in the economy's response to the credit shock. Figure 13 illustrates how the economy without transaction costs (dashed lines) behaves in response to this aggregate shock, and compares it with that of our baseline case with transaction costs (solid lines). Without transaction costs, the shock leads to a substantially larger decline in scrappage, used-car prices, and new-car sales relative to those of the baseline case; however, the volume of trade of used cars increases above its initial level, whereas it drops in the economy with transaction costs (as in the data). The key reason for these equilibrium dynamics is that in order to increase their liquid assets, many middle- and low-wealth households who own cars of quality $q_{2}$ respond to the credit shock by selling them and temporarily downgrading to cars of quality $q_{3}$. This force leads to an increase in supply (and thus in trading volume) of used cars of quality $q_{2}$, driving their price down further. This downgrading effect is so strong that cars of quality $q_{3}$ are in excess demand at the scrappage value $p_{N}$; thus, they temporarily trade at a higher price than $p_{N}$ while the economy adjusts to the shock.

By contrast, the volume of downgrading the aggregate shock induces is quantitatively small in our baseline calibration with transaction costs, because households anticipate that downgrading implies that they will incur transaction costs twice: First, when they downgrade; and second, 
when they re-upgrade their car in the near future, once the economy stabilizes toward its long-run stationary equilibrium.

Overall, this counterfactual case suggests that by preventing larger downgrading of durable goods than that observed in the data, transaction costs play an important role in dampening the effect of the shocks on secondary-market prices, and thus on new-car sales.

\subsection{Aggregate income shock}

We now further enrich our model by considering the joint effect of a tightening of the credit limit and of a negative aggregate income shock. Thus, this case includes additional realistic features of the Great Recession, during which both credit conditions and household incomes deteriorated. We parameterize the credit shock in the same way as in our baseline case of Section 6.1. Moreover, we approximate the output decline induced by the Great Recession by assuming that all households receive an exogenous negative shock equal to $2 \%$ of their income for 2 years, which in our calibration coincide with 2008 and $2009 .^{28}$

Figure 14 displays the transitional dynamics of our main variables of interest. The aggregate income shock amplifies the effects of the credit shock on car markets. Relative to the baseline case with the credit shock only, it leads to larger declines in scrappage and new-car purchases, which drop by approximately $35 \%$ relative to their initial values in the stationary equilibrium. Hence, through a combination of aggregate credit and income shocks, our model successfully accounts for a large fraction of the empirical decrease in car sales during the Great Recession displayed in Figure 1.

The income decline affects the patterns of car replacement through two channels. First, it directly amplifies our mechanism of delayed quality upgrade by making financial conditions even tighter for poor households close to the scrappage threshold. Second, it induces wealthier households to postpone their car replacement, regardless of feedback from the secondary market: They hold on to their intermediate-quality cars until after the recession. Hence, both demand and supply in the used-car market drop on impact, inducing a sizable decline in the volume of cars traded.

In Supplementary Appendix B.4, we perform an analysis of the separate roles of secondarymarket prices and transaction costs, similar to that of Section 6.2, but in this case with both credit and aggregate income shocks hitting the economy. The results are consistent with those of the baseline case with only a credit shock. Notably, this decomposition confirms that accounting for equilibrium in secondary markets is important in explaining the decline in new-car sales observed during the Great Recession.

We also study an aggregate income shock in the absence of credit tightening, under two alternative specifications. First, we consider a shock that hits all households symmetrically (as in the case analysed above). Whereas the income shock acts as a powerful amplifier for the credit tightening, we find that an aggregate income decline alone cannot account for the empirical patterns described in Section 3. When the borrowing limit does not change, the income shock induces price effects that do not match those observed in the data: In our flexible-price environment, the combination of low current income and expectations of higher future income

28. A decline in aggregate output allows us to account for a decline in both non-durable consumption and durable purchases. By adding an explicit modelling of the production of non-durable goods and assuming price rigidities or other frictions, our framework may be able to endogenously generate a decline in aggregate output in response to the credit shock. However, these additional features are beyond the scope of our paper, given our focus on durable goods markets. For models that endogenously generate output declines following similar financial shocks, see, for instance, Guerrieri and Lorenzoni (2017) and Huo and Ríos-Rull (2016). 

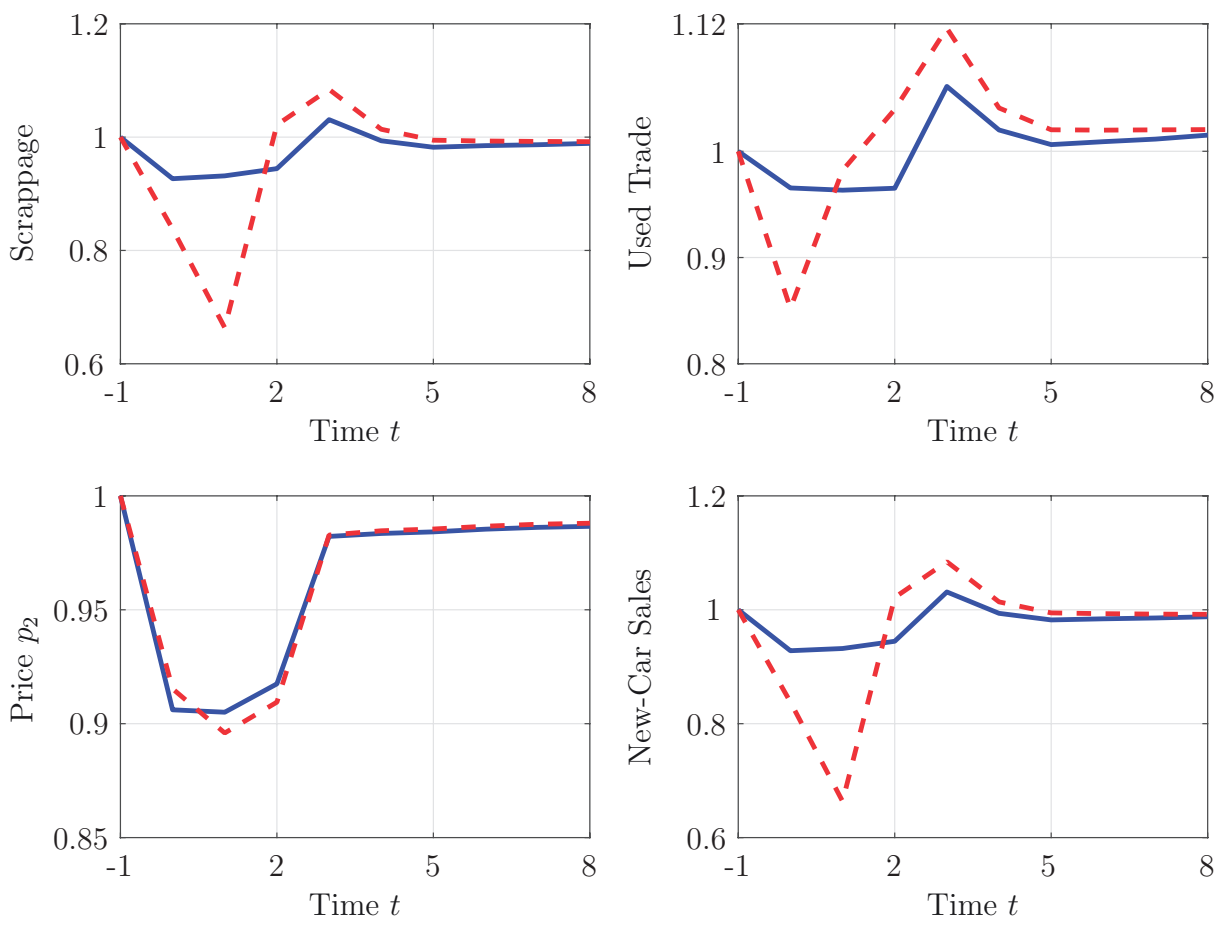

FIGURE 14

Credit and income shocks. The economy is in the stationary equilibrium at $t=-1$, and households learn about the new path of the borrowing limit and income at $t=0$. The horizontal axis displays time $t$. The top-left panel displays scrappage; the top-right panel the volume of trade of used cars; the bottom-left panel the price $p_{2}$ of quality- $q_{2}$ cars; and the bottom-right panel the sales of new cars. The solid line displays the baseline case with a credit shock only; the dashed line displays the case with credit and income shocks.

lead to an increase in the real interest rate; moreover, the decrease in both demand and supply of used cars implies that the income shock alone cannot generate a sizable drop in used-car prices. For these reasons, our model suggests that a quantitatively successful explanation of the dynamics described in Section 3 involves a combination of tighter credit conditions and an income decline.

Second, inspired by the empirical literature on the skewed effects of recessions (e.g. Guvenen et al., 2014), in Supplementary Appendix B.5, we explore the effects of an income shock that hits low-income households only. ${ }^{29}$ We find that a temporary income loss for lowincome households leads to qualitative effects similar to the credit tightening, which suggests that our main mechanism for delayed scrappage and replacement is general and may apply to several empirically relevant cases in which aggregate shocks affect the income-wealth distribution asymmetrically. Quantitatively, however, this version of the income shock, in isolation, also seems less powerful than the combination of credit shock and aggregate income shock illustrated in Figure 14.

29. The skewed income shock increases income uncertainty, as well. 


\subsection{Endogenous price of new durables}

So far, we have assumed that the marginal cost of producing new durables $p_{1}$ is an exogenous constant. To account for the modest decline in new-car prices in the Great Recession reported in Section 3, we now generalize our production technology for new durable goods, by assuming that the marginal cost (in terms of output good) is a function of the aggregate quantity produced. This experiment allows us to address the following question: what are the effects of a new-car price decline on used-car prices and new-car sales?

Specifically, we assume that the marginal cost of new durables at time $t$ equals

$$
p_{1, t}=c_{0}+c_{1}\left(x_{t}-\bar{x}\right),
$$

where $c_{0}$ and $c_{1}$ are positive coefficients, $x_{t}$ is aggregate production of quality- $q_{1}$ durables at time $t$, and $\bar{x}$ is the level of production in stationary equilibrium.

This linear "supply function" is consistent with curvature in the production function for new durables; specifically, with a quadratic total cost function. Durable producers are perfectly competitive: They take the path of the aggregate marginal cost as given, and set the output price equal to the marginal cost in each period. ${ }^{30}$ The baseline version of the model is the special case in which $c_{1}=0$.

To assess the quantitative role of endogenous new-price changes in the Great Recession, we focus on the version of the model with both a credit and an aggregate income shock. We calibrate $c_{1}=0.75$ to approximately match a $3 \%$ peak-to-trough decline in new-car prices, in line with the evidence based on the Dominion dataset and the CPI data reported in Section 3 and Supplementary Appendix A, respectively.

Figure 15 portrays the results of this analysis. As demand for durables of all qualities declines in the recession, new prices endogenously decline before recovering as the economy adjusts to the shock. We highlight two key equilibrium effects of the endogenous marginal cost of durables. First, because new and used cars are partially substitutable, the decline in new-car prices in the recession puts additional downward pressure on used-car prices, further deepening their drop (overall, approximately 15\%) relative to the baseline model with constant marginal cost. This effect improves the degree of success of our model in matching the empirical dynamics of used prices.

Second, the key price signal for households' replacement decisions from quality $q_{2}$ to quality $q_{1}$-i.e., the main driver of new sales-is their relative price. Although new cars are cheaper in the recession, the fact that $q_{2}$ cars lose even more value implies that the dampening effect of the new-price decline on the drop in new sales is limited. Quantitatively, the model with endogenous $p_{1}$ predicts a $25 \%$ decline in new-car sales.

Overall, we find that our main insights on the importance of secondary-market equilibrium for durable purchases are robust to the inclusion of curvature in the production of new cars. Consistent with our empirical analysis, the cost of replacing used cars with new ones still rises substantially during the crisis, thereby discouraging new sales; this is similar to our baseline result with exogenous new prices.

\subsection{Durables as collateral}

Our baseline case considers a constant credit limit $\phi$ that applies to all households, independent of their durable holdings. We now study a specification of the model in which household borrowing

30. For simplicity, and because of our focus on aggregate outcomes, we abstract from a more detailed modelling of the micro-structure of production, such as non-constant returns to scale at the firm level, entry, and exit. 

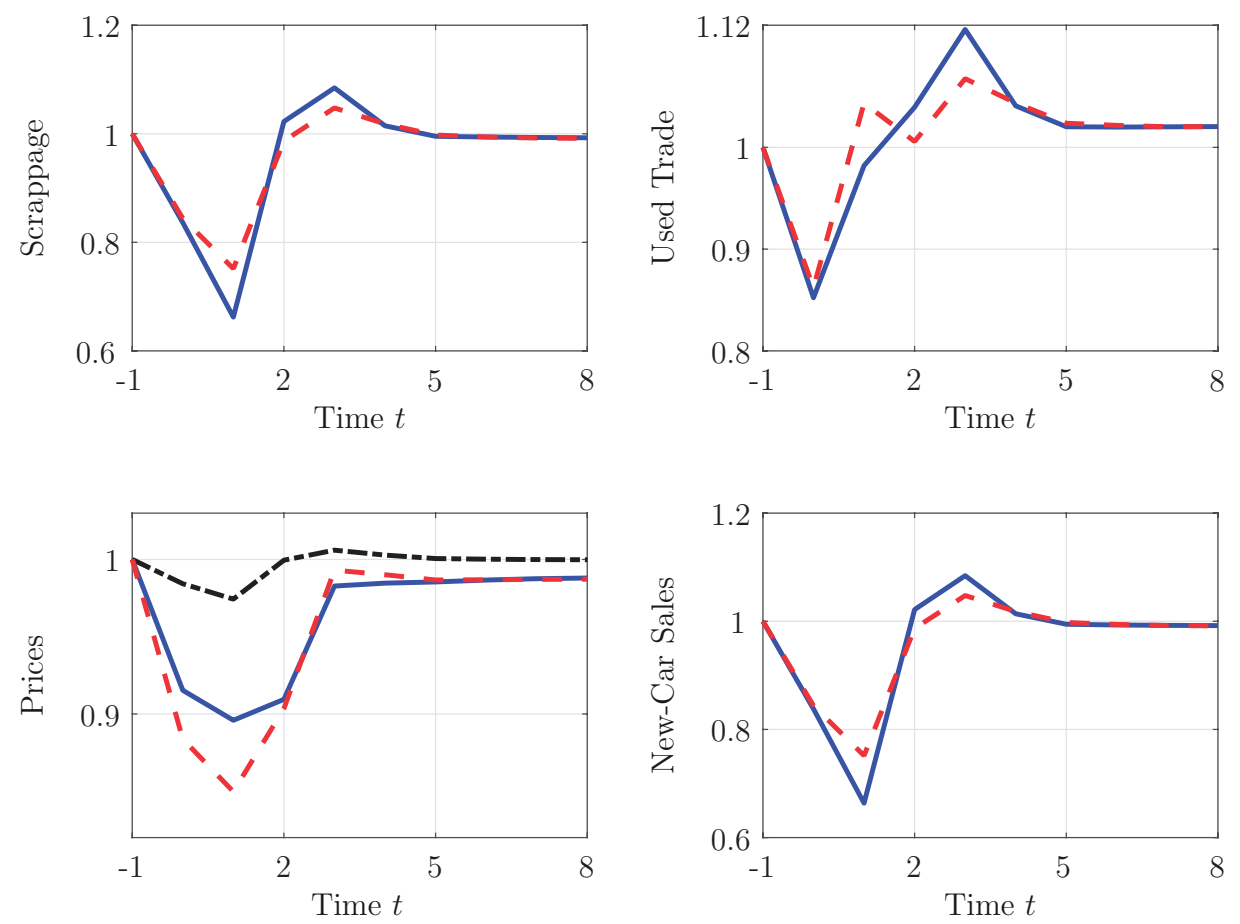

FIGURE 15

Credit and income shocks with endogenous new-car price. The economy is in the stationary equilibrium at $t=-1$, and households learn about the new path of the borrowing limit and income at $t=0$. The horizontal axis displays time $t$. The top-left panel displays scrappage; the top-right panel the volume of trade of used cars; the bottom-left panel the price $p_{2}$ of quality- $q_{2}$ cars; and the bottom-right panel the sales of new cars. The solid line displays the case with constant $p_{1}$; the dashed line displays the case with endogenous $p_{1}$. The dashed-dotted line displays the path of $p_{1}$ in the endogenous case.

limits depend on the expected resale value of their durables - that is, a collateral constraint. This analysis encompasses the case of car loans, although it applies more generally. We show that this modification reinforces the main mechanism of our model, which links a credit tightening to a drop in new durables purchase through a drop in resale prices. Moreover, this modification smooths the recovery of durable goods markets once the borrowing limit stays at its new long-run value.

To introduce a role for durables as collateral, we replace equation (3) with the following constraint:

$$
b_{i, t+1} \geq \phi_{t}\left(\chi_{0}+\chi_{1} \mathrm{E}_{t}\left[p_{n_{i, t+1}} \mid \tilde{n}_{i t}\right]\right),
$$

where the term $\phi_{t}$ denotes the exogenously time-varying level of the credit limit. This collateral constraint allows for both uncollateralized debt, through the term $\chi_{0}$, and collateralized car loans, through the term $\chi_{1} \mathrm{E}_{t}\left[p_{n_{i, t+1}} \mid \tilde{n}_{i t}\right]$. The aggregate shock $\phi_{t}$ affects both components of the credit limit. Equation (11) highlights the fact that the expected collateral value depends on the chosen car quality $\tilde{n}_{i t}$. Higher quality implies a higher expected equilibrium resale value, and thus a larger borrowing capacity. 

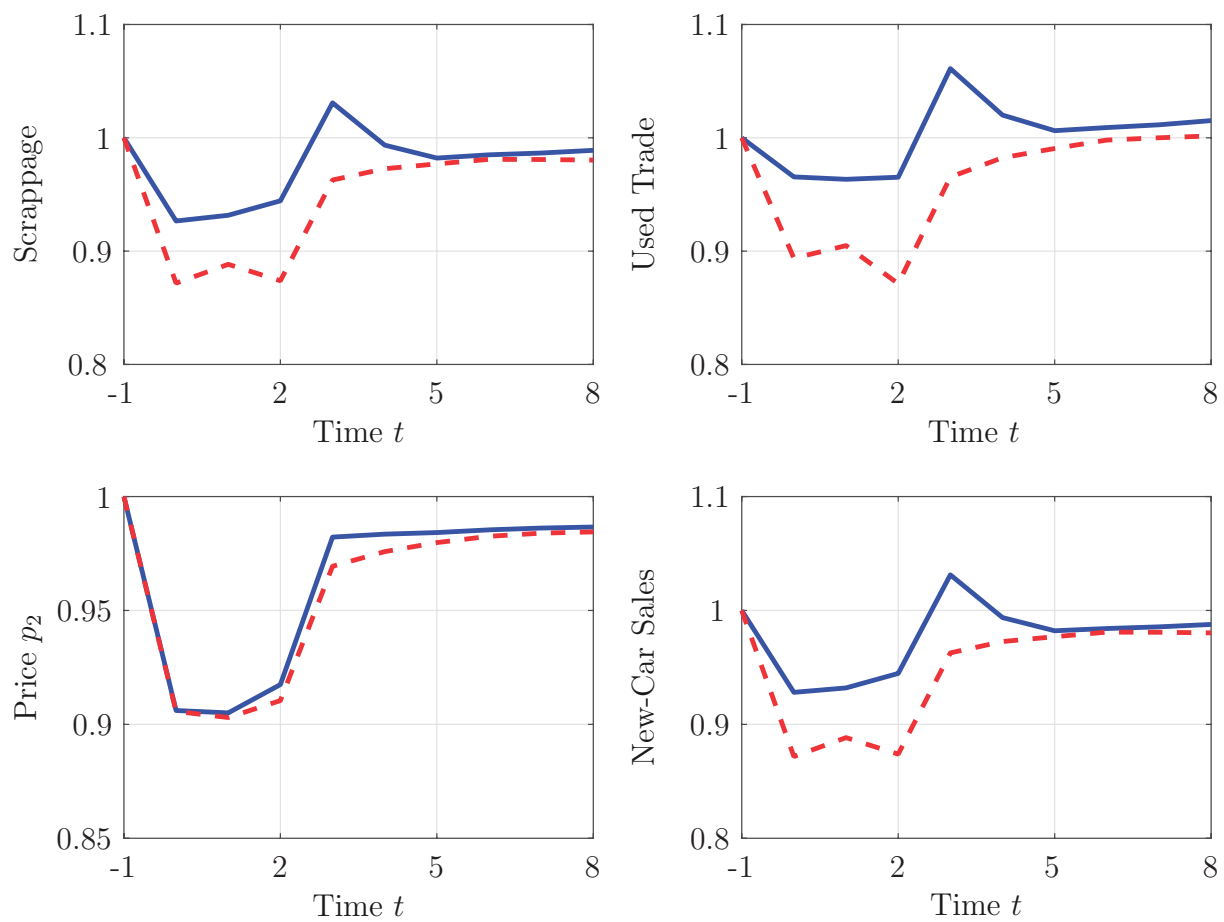

FIGURE 16

Shock to the collateral constraint. The economy is in stationary equilibrium at $t=-1$. Households learn about the new path of the borrowing limit $t=0$. The horizontal axis displays time $t$. The top-left panel displays scrappage; the top-right panel the volume of trade of used car; the bottom-left panel the price $p_{2}$ of quality- $q_{2}$ cars; and the bottom-right panel the sales of new cars. The solid line displays the baseline case and the dashed line displays the case with collateral constraint.

We set $\chi_{1}=0.85$, an intermediate value in the empirical range of loan-to-value ratios for auto loans. ${ }^{31}$ We then set $\chi_{0}=0.8$ to make total household debt close to its counterpart in the economy without collateral, i.e., the baseline model, for comparison purposes. As in our baseline case, we consider a shock that changes $\phi_{t}$ from a steady-state value of -1 to a new steady-state value of -0.4 ., which induces a path for the interest rate close to its empirical counterpart. To isolate the role of collateral, in this analysis we abstract from aggregate income changes and endogenous new-durables prices.

Figure 16 illustrates the transitional dynamics of our variables of interest. Qualitatively, the collateral constraint does not change the outcomes relative to the baseline shock. Quantitatively, we observe a substantially larger decline in scrappage and new-car sales than in the baseline case, whereas the dynamics of used-car prices are broadly similar. Most notably, the drop in new-car sales (bottom-right panel) is almost twice as large as that obtained in the baseline case, thereby accounting for approximately half of the decline in new-car sales displayed in Figure 1. The reason for this larger drop is that the presence of resale values in the credit constraints induces an amplification effect: expected low resale prices for used cars further tighten credit limits for new-car buyers after the aggregate shock hits.

31. For instance, aggregate data on auto loans from the Federal Reserve Board of Governors report loan-to-value ratios around $90 \%$, and data from NADA suggest an average value slightly below $80 \%$. 
This amplification effect is closely related to a standard financial accelerator effect à la Kiyotaki and Moore (1997), with one important difference. In our model, there is a clear distinction between new-durable prices and resale values, in contrast to most of the literature. While resale values drop in bad times, new prices do not. This difference makes new purchases particularly unattractive during downturns, which induces a stronger amplification mechanism than in models with a single price of durable (or capital) goods.

\section{POLICY EVALUATION: DURABLE-REPLACEMENT SUBSIDIES}

We now use our framework to study the effects of a fiscal intervention aimed at stimulating household spending on durable goods during a credit crunch, similar to the car-replacement stimulus implemented in the U.S. in 2009 (the Cars Allowance Rebate System, commonly referred to as "Cash for Clunkers"). Similar subsidies are common across countries and across several recession episodes (e.g. Adda and Cooper, 2000, provide a structural evaluation of two interventions in France in the 1990s).

In our framework, secondary markets play an important role in the transmission of these policy interventions. Thus, we introduce a durable-replacement subsidy immediately after the credit-supply shock discussed in Section 6.1 hits the economy. Specifically, in the first year in which the credit shock hits, the government offers a subsidy equal to $10 \%$ of the price of a new car to owners of cars of quality $q_{3}$ who choose to scrap their cars and replace them with a new car (i.e. of quality $q_{1}$ ) in that year. ${ }^{32}$ We assume the government initially finances this policy by running a deficit; after 10 years, the government raises lump-sum taxes in order to gradually reduce the debt to its initial steady-state value. Formally, taxes equal:

$$
\tau_{t}= \begin{cases}\tau_{t}^{*} & \text { if } \quad t<10 \\ \tau_{t}^{*}+\psi\left(b_{G t}-b_{G}^{*}\right) & \text { if } \quad t \geq 10\end{cases}
$$

where $\tau_{t}^{*}$ and $b_{G}^{*}$ are taxes and government debt in the baseline case analysed in Section 6.1; we set $\psi=0.06$ to achieve convergence of government debt to its steady-state value within 30 years from the policy implementation.

In Figure 17, we compare the dynamics of the key variables of interest under the policy (dashed line) with those obtained in the baseline case with no subsidies (solid line). The direct effect of the policy is to attenuate the fall in scrappage and new-car sales while the subsidies are available. However, general-equilibrium effects dampen the stimulus of these subsidies. Most notably, the policy induces a further decline in the price of used cars (quality $q_{2}$ ) and a larger fall in the volume of trade, relative to the baseline case, because in the baseline case, most households that scrap their $q_{3}$-cars replace them with $q_{2}$-cars rather than new $q_{1}$-ones. However, the stimulus leads households to substitute away from cars of quality $q_{2}$ and toward cars of quality $q_{1}$. As a result, demand for cars of quality $q_{2}$ falls, triggering a drop in their price and their volume of trade. In turn, the fire-sales $p_{2}$ prices urge wealthy households-who, in the absence of the policy, would

32. The Car Allowance Rebate System offered subsidies between $\$ 3,500$ and $\$ 4,500$, depending on car models; that is, approximately $10 \%$ of the average new car price. However, these subsidies were only available during the months of July and August 2009, and thus our yearly calibration does not allow us to exactly match the timing aspect of the policy. Moreover, the Car Allowance Rebate System did not involve a minimum age requirement in order for scrapped vehicles to qualify for the subsidy (this aspect differs from the related French policies studied by Adda and Cooper, 2000). Eligibility depended largely on fuel efficiency and on other attributes that our model abstracts from. In practice, however, most scrapped cars were relatively old. For simplicity, we focus on an eligibility criterion based on our notion of car quality, but given the size of the subsidy, extending eligibility to higher-quality cars would not affect the results. 

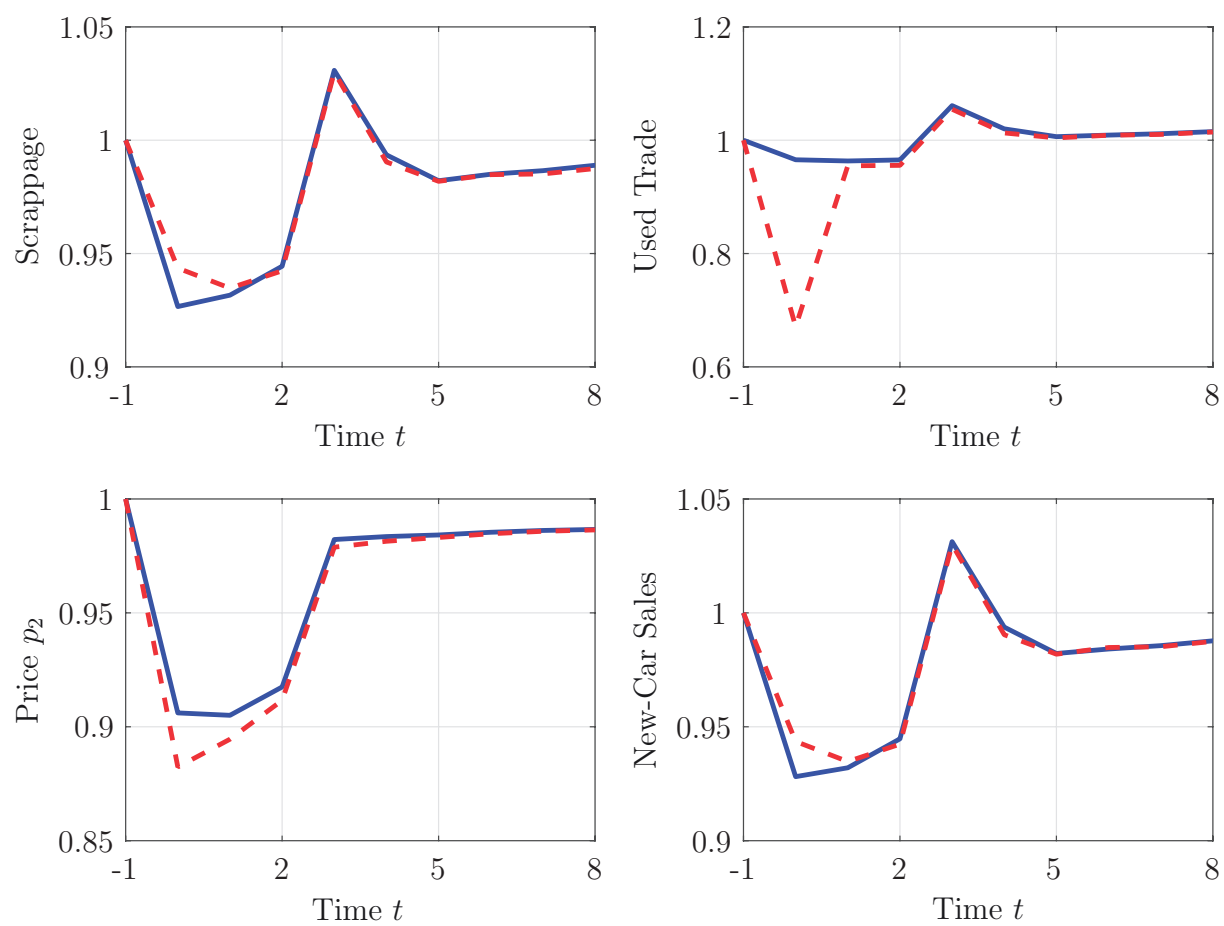

FIGURE 17

Credit shock and durable-replacement subsidy. The economy is in the stationary equilibrium at $t=-1$, and households learn about the new path of the borrowing limit and policy at $t=0$. The horizontal axis displays time $t$. The top-left panel displays scrappage; the top-right panel the volume of trade of used cars; the bottom-left panel the price $p_{2}$ of quality- $q_{2}$ cars; and the bottom-right panel the sales of new cars. The solid line displays the baseline case; the dashed line the case with replacement subsidies.

trade in their $q_{2}$ cars for $q_{1}$ cars-to delay these replacement purchases. Hence, the subsidies are less effective than models that do not include general-equilibrium effects would predict.

Overall, this analysis highlights that these subsidies generate two types of substitution: (1) substitution from $q_{2}$-cars to $q_{1}$-cars, which seems broadly consistent with the results of Hoekstra et al. (2017), who find that households tended to purchase less expensive and smaller new vehicles during the period of the Car Allowance Rebate System and (2) intertemporal substitution in scrappage and demand for new cars only from the near future, which is consistent with the empirical evidence of Mian and Sufi (2012) and Hoekstra et al. (2017). Both of these substitution channels limit the effectiveness of the policy in terms of stimulating current expenditures on durables. ${ }^{33}$

33. Because we do not model explicitly the production of non-durable goods and do not assume nominal rigidities, labour-market frictions, or other sources of inefficiency that might give rise to aggregate-demand externalities, our framework is not designed to quantify the desirability of this type of fiscal stimulus. Hence, in terms of welfare, our model implies that the policy has effects of negligible magnitude. A richer model that combines our equilibrium mechanism with other macroeconomic frictions may allow us to study normative questions on the optimal design of replacement subsidies in response to aggregate shocks. 


\section{CONCLUSION}

In this article, we propose a novel general-equilibrium model of endogenous illiquidity of consumer durable goods to account for the aggregate dynamics of durable expenditures. Our equilibrium notion of illiquidity stems from the imperfect substitutability across durables of different qualities, which trade at market-clearing prices. Aggregate shocks lead to changes in the relative prices of durables of different qualities, affecting the replacement cost of higher-quality goods. We show that our model matches several striking patterns of U.S. car markets during the Great Recession.

We believe that car markets represent an ideal setting in which to study our mechanism, since we can measure relative price movements across goods of different qualities quite accurately. Nevertheless, in future research we hope to apply the key insights of our mechanism to housing markets as well, in which households climb a "property ladder" as their income increases.

Acknowledgments. We are grateful to the Editor (Veronica Guerrieri) and to four anonymous referees for insightful comments that substantially improved the paper; to Charles Murry for providing data; and to Pat Bayer, Julieta Caunedo, Russell Cooper, Wouter den Haan, Thomas Drechsel, Carlos Garriga, Hugo Hopenhayn, Julian Kozlowski, Adriano Rampini, Arlene Wong, and many conference and seminar audiences for helpful suggestions. Chang He, Eugene Tan, and Alessandro Villa provided excellent research assistance. Alessandro Gavazza gratefully acknowledges support from the European Research Council (ERC-Consolidator grant award no. 771004); Andrea Lanteri gratefully acknowledges support from the National Science Foundation (award no. SES 1756992).

\section{Supplementary Data}

Supplementary data are available at Review of Economic Studies online. And the replication packages are available at http://doi.org/10.5281/zenodo.4471687.

\section{Data Availability Statement}

The data and the code underlying this article are available in the Zenodo repository, at http://doi.org/ 10.5281/zenodo.4471687.

\section{REFERENCES}

ADDA, J. and COOPER, R. (2000), "Balladurette and Juppette: A Discrete Analysis of Scrapping Subsidies", Journal of Political Economy, 108, 778-806.

(2006), "The Dynamics of Car Sales: A Discrete Choice Approach” (Working Paper 7785, National Bureau of Economic Research).

AIYAGARI, S. R. (1994), "Uninsured Idiosyncratic Risk and Aggregate Saving”, The Quarterly Journal of Economics, 109, 659-684.

ANDERSON, S. P. and GINSBURGH, V. A. (1994), "Price Discrimination via Second-Hand Markets", European Economic Review, 38, 23-44.

ANENBERG, E. and BAYER, P. (2020), "Endogenous Sources of Volatility in Housing Markets: The Joint Buyer-Seller Problem", International Economic Review, 61, 1195-1228.

ATALAY, E. (2017), "How Important are Sectoral Shocks?", American Economic Journal: Macroeconomics, 9, $254-280$.

ATTANASIO, O. (2000), "Consumer Durables and Inertial Behavior: Estimation and Aggregation of (S,s) Rules for Automobile Purchases", The Review of Economic Studies, 67, 667-696.

BENMELECH, E., MEISENZAHL, R. R. and RAMCHARAN, R. (2017), "The Real Effects of Liquidity During the Financial Crisis: Evidence from Automobiles", The Quarterly Journal of Economics, 132, 317-365.

BERGER, D. and VAVRA, J. (2015), "Consumption Dynamics During Recessions", Econometrica, 83, 101-154.

BERNANKE, B. (1985), "Adjustment Costs, Durables, and Aggregate Consumption", Journal of Monetary Economics, 15, 41-68.

(2018), “The Real Effects of Disrupted Credit: Evidence from the Global Financial Crisis", Brookings Papers on Economic Activity (Brookings Institution Press), 251-342.

BEWLEY, T. (1986), "Stationary Monetary Equilibrium with a Continuum of Independently Fluctuating Consumers", in Hildenbrand, W. AND Mas-Colell, A. (eds) Contributions to Mathematical Economics in Honor of Gerard Debreu (Amsterdam, Netherlands: Elsevier Science) 79-102.

CABALLERO, R. J. (1993), "Durable Goods: An Explanation for Their Slow Adjustment”, Journal of Political Economy, 101), 351-384. 
CAPLIN, A. and LEAHY, J. V. (2006), "Equilibrium in a Durable Goods Market with Lumpy Adjustment", Journal of Economic Theory, 128, 187-213.

CHAFWEHÉ, B. (2017), "Durable Goods Markets in Heterogeneous Agents Economies" (Discussion Paper 2017-21, IRES Universitè catholique de Louvain).

CHEN, J., ESTEBAN, S. and SHUM, M. (2013), "When Do Secondary Markets Harm Firms?", American Economic Review, 103, 2911-2934.

COOPER, R. and HALTIWANGER, J. (1993), "The Aggregate Implications of Machine Replacement: Theory and Evidence", American Economic Review, 83, 360-382.

COOPER, R., HALTIWANGER, J. and POWER, L. (1999), "Machine Replacement and the Business Cycle: Lumps and Bumps", American Economic Review, 89, 921-946.

DOMINION DEALER SOLUTIONS (2019), "Data on New-Car Prices, 2004-2012" Norfolk, VA.

DUPOR, B., LI, R., MEHKARI, S. and TSAI, Y.-C. (2018), “The 2008 U.S. Auto Market Collapse” (Working Paper 2018-019A, Federal Reserve Bank of St. Louis).

EBERLY, J. C. (1994), “Adjustment of Consumers' Durables Stocks: Evidence from Automobile Purchases”, Journal of Political Economy, 102, 403-436.

FAVILUKIS, J., LUDVIGSON, S. and VAN NIEUWERBURGH, S. (2017), “The Macroeconomic Effects of Housing Wealth, Housing Finance, and Limited Risk Sharing in General Equilibrium”, Journal of Political Economy, 125, 140-223.

FEDERAL HIGHWAY ADMINISTRATION (2017), "Stock of Registered Vehicles, 2005-2014” Washington, D.C.

FLODÉN, M. and LINDÉ, J. (2001), "Idiosyncratic Risk in the U.S. and in Sweden: Is There a Role for Government Insurance?", Review of Economic Dynamics, 4, 81-108.

GARRIGA, C. and HEDLUND, A. (2020), "Mortgage Debt, Consumption, and Illiquid Housing Markets in the Great Recession", American Economic Review, 110, 1603-1634.

GAVAZZA, A. (2010), "Asset Liquidity and Financial Contracts: Evidence from Aircraft Leases", Journal of Financial Economics, 95, 62-84.

GAVAZZA, A., LIZZERI, A. and ROKETSKIY, N. (2014), “A Quantitative Analysis of the Used-Car Market”, American Economic Review, 104, 3668-3700.

GERTLER, M. and GILCHRIST, S. (2018), "What Happened: Financial Factors in the Great Recession", Journal of Economic Perspectives, 32, 3-30.

GROSSMAN, S. J. and LAROQUE, G. (1990), "Asset Pricing and Optimal Portfolio Choice in the Presence of Illiquid Durable Consumption", Econometrica, 58, 25-51.

GUERRIERI, L. and IACOVIELLO, M. (2017), "Collateral Constraints and Macroeconomic Asymmetries", Journal of Monetary Economics, 90, 28-49.

GUERRIERI, V. and LORENZONI, G. (2017), "Credit Crises, Precautionary Savings, and the Liquidity Trap”, The Quarterly Journal of Economics, 132, 1427-1467.

GUVENEN, F., OZKAN, S. and SONG, J. (2014), "The Nature of Countercyclical Income Risk", Journal of Political Economy, 122, 621-660.

HOEKSTRA, M., PULLER, S. L. and WEST, J. (2017), "Cash for Corollas: When Stimulus Reduces Spending”, American Economic Journal: Applied Economics, 9, 1-35.

HUGGETT, M. (1993), "The Risk-Free Rate in Heteregeneous-Agent Incomplete-Insurance Economies”, Journal of Economic Dynamics and Control, 17, 953-969.

HUO, Z. and RÍOS-RULL, J. V. (2016), "Financial Frictions, Asset Prices, and the Great Recession" (Mimeo, University of Pennsylvania).

JACOBSEN, M. R. and VAN BENTHEM, A. A. (2015), "Vehicle Scrappage and Gasoline Policy", American Economic Review, 105, 1312-1338.

JAIMOVICH, N., REBELO, S. and WONG, A. (2019), "Trading Down and the Business Cycle", Journal of Monetary Economics, 102, 96-121.

KAPLAN, G. and VIOLANTE, G. L. (2014), "A Model of the Consumption Response to Fiscal Stimulus Payments", Econometrica, 82, 1199-1239.

KIYOTAKI, N. and MOORE, J. (1997), "Credit Cycles”, Journal of Political Economy, 105, 211-248.

LANDVOIGT, T., PIAZZESI, M. and SCHNEIDER, M. (2015), "The Housing Market(s) of San Diego", American Economic Review, 105, 1371-1407.

LANTERI, A. (2018), “The Market for Used Capital: Endogenous Irreversibility and Reallocation over the Business Cycle", American Economic Review, 108, 2383-2419.

LEAHY, J. V. and ZEIRA, J. (2005), “The Timing of Purchases and Aggregate Fluctuations", Review of Economic Studies, 72, 1127-1151.

MANKIW, G. (1982), "Hall's Consumption Hypothesis and Durable Goods", Journal of Monetary Economics, 10, 417-425.

MIAN, A. and SUFI, A. (2012), "The Effects of Fiscal Stimulus: Evidence from the 2009 Cash for Clunkers Program", The Quarterly Journal of Economics, 127, 1107-1142.

NATIONAL AUTOMOBILE DEALERS ASSOCIATION (2015), "New Vehicle Leasing: Facts, Figures and Future Considerations" (White Paper).

- (2016), "Data on Used-Car Prices, 2003-2012" Tysons, VA.

OH, H. (2019), "The Role of Durables Replacement and Second-Hand Markets in a Business-Cycle Model", Journal of Money, Credit and Banking, 51, 761-786. 
ORTALO-MAGNÉ, F. and RADY, S. (2006), "Housing Market Dynamics: On the Contribution of Income Shocks and Credit Constraints", The Review of Economic Studies, 73, 459-485.

RAMCHARAN, R., VERANI, S. and VAN DEN HEUVEL, S. (2016), "From Wall Street to Main Street: The Impact of the Financial Crisis on Consumer Credit Supply", The Journal of Finance, 71, 1323-1356.

RAMPINI, A. A. (2019), "Financing Durable Assets", American Economic Review, 109, 664-701.

ROUWENHORST, K. G. (1995), “Asset Pricing Implication of Equilibrium Business Cycle Models”, in Cooley, T. J. (ed.) Frontiers of Business Cycle Research, chapter 10 (Princeton, NJ, USA: Princeton University Press) 294-330.

RUST, J. (1985), "Stationary Equilibrium in a Market for Durable Assets", Econometrica, 53, 783-805.

STEIN, J. (1995), "Prices and Trading Volume in the Housing Market: A Model with Down-Payment Effects", The Quarterly Journal of Economics, 110, 379-406.

STOLYAROV, D. (2002), “Turnover of Used Durables in a Stationary Equilibrium: Are Older Goods Traded More?", Journal of Political Economy, 110, 1390-1413.

U.S. BUREAU OF ECONOMIC ANALYSIS (2017), "New-Vehicle Sales 2005-2014” Washington, D.C.

U.S. BUREAU OF LABOR STATISTICS (2013), “Consumer Expenditure Survey, 2003-2012” Washington, D.C. 